\title{
Quantum microRNA network analysis in gastric and esophageal cancers: Xenotropic plant microRNAs cure from cancerous paradox via Helicobacter pylori infection
}

\author{
Yoichi R Fujii* \\ Kawada-Cho, 106-6, Astuta-Ku, Nagoya, Japan
}

\begin{abstract}
Objective: We have previously shown the aetiology of cancer progression in breast, lung, pancreatic and colorectal cancers by the circulating microRNA (miRNA) panel using the miRNA entangling target sorter (METS) analysis with quantum miRNA language. It has been unveiled by the METS analysis that miRNA/miRNA quantum programming code would control oncogenesis via the hub miRNA in the miRNA biomarker panel. While the etiologic implication between gastric cancer and Helicobacter pylori $(H$. pylori) is still not cleared, many reports have statistically supported the efficacy of eradication of $H$. pylori to reduce the risk of gastric cancer.

Material and methods: To elucidate etiological significance of the biomarker miRNA panel in $H$. pylori infection, the data was firstly extracted from database to predict a feasible explanation for $H$. pylori pathogenicity upon cancer in the stomach. The aetiologies of gastric and oesophageal cancers, and $H$. pylori infection with or without vegetables and fruits were dynamically simulated by the computation using the quantum miRNA language with the METS. Statistical analysis was also performed by machine learning.

Results: In the quantum network, $H$. pylori infection showed proton pump inhibition, and insulin-like growth factor 1 receptor (IGF1R) expression was reduced as the common factor between gastric cancer stage I and $H$. pylori infection; however, both were pathogenic but not seriously oncogenic. Statistically, chronic $H$. pylori infection itself was not be significant upon oncogenic.

Conclusions: The environmental stress including mal-diets, such as long-term less fresh vegetable and fruit, would dysregulate miRNA expression, additionally it may contribute most for increasing risk of gastric cancer through enhancing glucose metabolic pathway on a paradox in Zen Buddhism riddle via IGF1R inhibition by $H$. pylori infection. Thus, xenotropic plant miRNAs (xenomiRNAs) from fresh vegetables and fruits may cure from paradoxical tumorigenesis with $H$. pylori infection.
\end{abstract}

\section{Introduction}

Gastric cancer and oesophageal squamous cell carcinoma (ESCC) have been the leading causes of cancer mortality in the world and the high incident rate in Asian with a total 5-years overall survival rate of $18-25 \%[1,2]$. Risk factors of gastric cancer resemble those of ESCC, which are Tobacco, alcohol, chemical exposure, diet and obesity, etc. The other one of gastric cancer is associated with Helicobacter pylori (H. pylori) infection but ESCC is not. Drs. Marshall B. and Warren R. were awarded the 2005 Nobel Prize for the discovery of $H$. pylori, which now is the dominant risk factor of gastric cancer; however, some people in Asia has persistently infected with $H$. pylori infection at high rates but do not suffer from high incident rates of gastric cancer because of availability of fresh fruits and vegetables all year round $[3,4]$. H. pylori infection reduces the risk of oesophageal inflammation and ESCC and shows to protect against cardia gastric cancer $[5,6]$. Thus, although the role of booster might be statistically shown in gastric cancer development under $H$. pylori infection, the relation of oncogenesis between $H$. pylori infection and host in gastric cancer is complex.

MicroRNA (miRNA) would be a quantum programming code device of lives because most of all protein genes are directly or indirectly tuned by miRNAs and it controls development, metabolism, cardiac system, neural system, immune system, infection and cancer. Highly dimensional quantum interaction of miRNA/miRNA has been correlated with context score of miRNA/mRNA the prediction tool, which is calculated by the sum of site-type specific, 3' UTR pairing, local A or U presence, and position contributions [7-9]. miRNA is circulated into the circulating system of human with stable extracellular form, such as in the exosomes, therefore, circulating miRNAs are now considered and clinically trialed as various disease biomarkers. Biomarker panel of miRNAs has been examined in diagnosis and prognosis of gastric cancer [10-13], oesophageal cancer [14-19] and $H$. pylori infection $[10,20]$. To elucidate a miRNA gene specific character of high dimension coherence in the RNA wave 2000, the ones for all and all for ones' relation between miRNAs and target mRNAs, we have previously shown the etiologic characters of Alzheimer's disease, and breast, pancreatic, lung and colorectal cancers by the miRNA memory package (MMP) from the circulating miRNA panel using the miRNA entangling target sorter (METS) analysis with quantum miRNA language $[21,22]$.

${ }^{\star}$ Correspondence to: Yoichi Robertus Fujii, Kawada-Cho, 106-6, Astuta-Ku, Nagoya, Japan, Tel: +81-52-682-7003; E-mail: fatfuji@hotmail.co.jp

key words: microRNA, xenomiRNA, gastric cancer, esophageal cancer, plant, food, machine learning

Received: September 02, 2019; Accepted: September 20, 2019; Published: September 23, 2019 
In this paper, for further understanding of the etiologic implication under quantum miRNA language between miRNA/miRNA program and mRNA targets, H. pylori pathogenicity concerning foods was investigated by METS analysis in gastric and oesophageal cancers.

\section{Materials and methods}

\section{Data base usage}

To review the validated data for miRNAs and cancers, PubMed (www.ncbi.nlm.gov/pubmed/) and Google Scholar (https://scholar. google.co.jp) were used. Total information content was 1,060, 2,822 and 256 in oesophageal and gastric cancers, and H. pylori infection, respectively. The gene function of protein was searched by GeneCards (www.genecards.org). Protein ontology was investigated by GO enrichment analysis powered by PANTHER in Geneontology (geneontology.org).

\section{Data mining}

About data mining, biomarker miRNAs were selected by; 1) data from serum or plasma, 2) showed in two or more references, 3 ) cleared in expression levels of up- and down-regulation (Table 1).

\section{METS simulation}

The physicochemical interaction has been calculated by METS between miRNA/miRNAs using the quantum miRNA language [21]. Data of the multi-targets of the microRNA memory package (MMP) were extracted from TargetScan Human 7.2 (www.targetscan.org/ vert_72/) and miRTarBase Ver. 8.0 (mirtarbase.cuhk.edu.cn/php/ search.php). Target protein/protein interaction and cluster were searched by String Ver. 11.0 (https://string-db.org/cgi/input.pl). The hub of miRNAs in cancers and $H$. pylori infection was selected by the clusters of functional protein/protein interaction (Table 1).

\section{Frequency DNS}
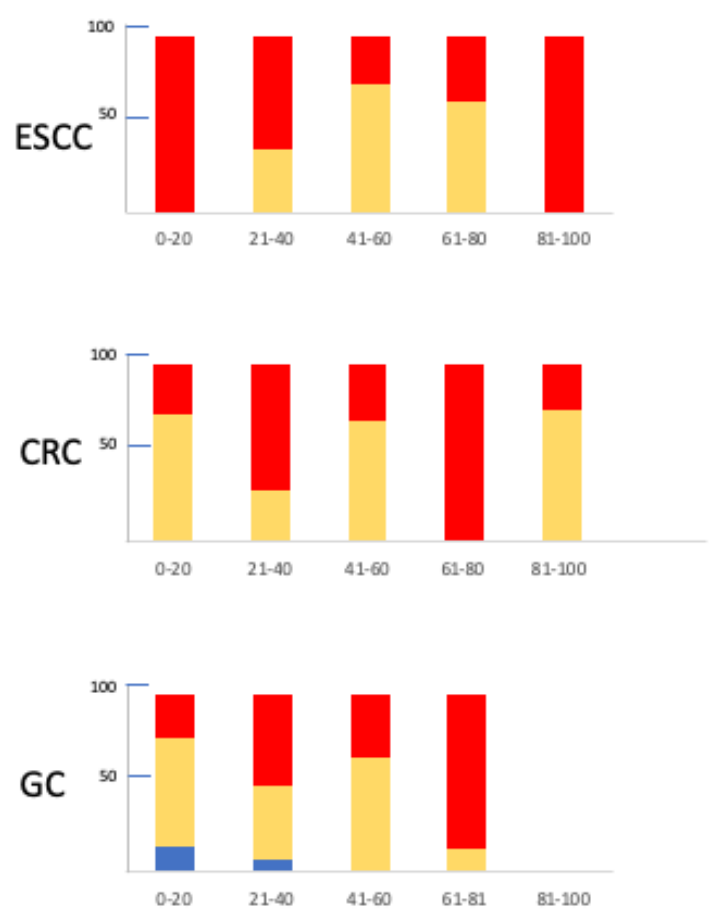

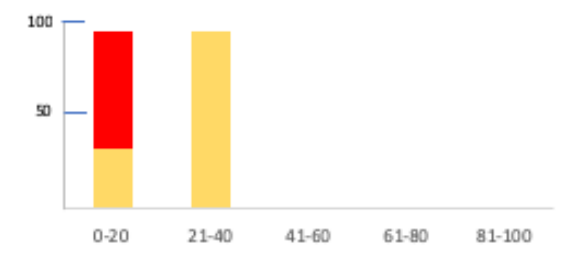

\section{Food miRNA functionally analogy analysis}

The functional analogy of miRNAs was performed as previously described data processing between human miRNAs and human immunodeficiency virus type 1 nef/3' LTR miRNA $[9,21,23]$. The plant miRNAs were homologically compared with human miRNAs data in miRbase Ver. 22.1 (miRbase.org) by MirCompare (160.80.35.140/ MirCompare/). The secondary structure of plant miRNAs to the target regions were computed by mfold (mfold.rit.albany.edu) and CentroidFold (rtools.cbrc.jp/centroidfold).

\section{Statistic tools}

The valuation of statistical significance for carcinogenic pathology in the METS simulation was performed by the area under the curve (AUC) in receiver operating characteristic (ROC) or the $\chi^{2}$-based Cochran's Q test using BellCurve for Excel (Social Survey Research Information Co. Ltd., Tokyo, Japan). Accuracy and precision of the miRNAs' relation with ESCC and gastric cancer were computed by machine learning using Prediction One Ver. 05.09.19 (Sony Network Communications Inc., Tokyo, Japan).

\section{Results and discussion}

\section{Distribution of quantum energy in gastric and oesophageal cancers}

In oesophageal and gastric cancers (ESCC and GC), the frequency and total amount of double nexus score (DNS) on each layer of quantum core region (QCR) were calculated and compared with those in previously described colorectal cancer (CRC) (Figure 1) [24].

Quantum energy frequency of stage I-IV oesophageal, gastric or colorectal cancers was widely spread among layers (Figure 1, red bars). DNS amounts of the hub miRNA in stage I-IV oesophageal and

\section{Hub miRNA DNS amounts}
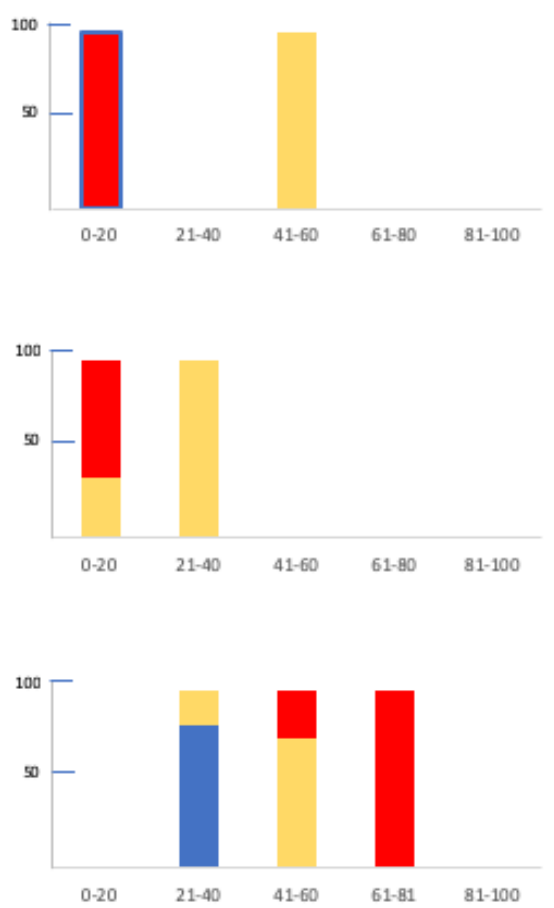

Figure 1. Distribution of quantum energy in gastric and oesophageal cancers. Frequency of DNS and DNS amounts in the miRNA hub were calculated in each layer (5 QCRs) in METS analysis of oesophageal cancer (ESCC), colorectal cancer (CRC) and gastric cancer (GC). 
Table 1. miRNA biomarkers in gastric cancer and ESCC

\begin{tabular}{|c|c|c|c|c|}
\hline \multicolumn{2}{|c|}{ Cancer and infection } & \multicolumn{3}{|c|}{ miRNA information } \\
\hline & Stage & miRNA* & Level & SNS \\
\hline \multirow[t]{8}{*}{ GC } & I & miR-21-5p & up & 5 \\
\hline & & miR-223-5p & up & 6 \\
\hline & & miR-218-1-3p & down & 6 \\
\hline & & miR-16-5p & up & 9 \\
\hline & & miR-25-5p & up & 9 \\
\hline & & miR-92a-1-5p & up & 9 \\
\hline & & miR-451a & up & 6 \\
\hline & & miR-486-5p & up & 6 \\
\hline \multirow[t]{6}{*}{ GC } & I-IV & miR-17-5p & up & 7 \\
\hline & & $\mathrm{miR}-106 \mathrm{a} / \mathrm{b}-5 \mathrm{p}$ & up & 7 \\
\hline & & miR-21-5p & up & 5 \\
\hline & & let-7a-5p & down & 8 \\
\hline & & miR-19a-5p & up & 4 \\
\hline & & miR-92a-1-5p & up & 9 \\
\hline \multirow[t]{9}{*}{ ESCC } & 0-I & $\operatorname{miR}-21-5 p$ & up & 5 \\
\hline & & $\operatorname{miR}-223-5 p$ & up & 6 \\
\hline & & miR-25-5p & up & 9 \\
\hline & & $\operatorname{miR}-375$ & down & 7 \\
\hline & & miR-106a-5p & up & 7 \\
\hline & & miR-18a-5p & up & 7 \\
\hline & & miR-20b-5p & up & 7 \\
\hline & & $\operatorname{miR}-486-5 p$ & up & 6 \\
\hline & & miR-584-5p & up & 8 \\
\hline \multirow[t]{9}{*}{ ESCC } & IV & miR-16-5p & up & 6 \\
\hline & & miR-451a & up & 3 \\
\hline & & miR-574-5p & up & 11 \\
\hline & & miR-21-5p & up & 5 \\
\hline & & miR-25-5p & up & 9 \\
\hline & & miR-145-5p & up & 4 \\
\hline & & miR-129-5p & up & 7 \\
\hline & & miR-29c-5p & down & 5 \\
\hline & & miR-205-5p & down & 4 \\
\hline \multicolumn{2}{|c|}{ H. pylori infection } & miR-28-3p & up & 6 \\
\hline & & miR-143-3p & up & 6 \\
\hline & & miR-151a-3p & up & 6 \\
\hline & & miR-148a-3p & up & 4 \\
\hline & & miR-223-5p & up & 6 \\
\hline
\end{tabular}

colorectal cancers were located into a narrow and lowest QCR layer, $0-20$, and hub miRNA expression was downregulated in oesophageal cancer's QCR (Figure 1, a red plus blue border bar). On the other hand, the frequency DNS and DNS amounts of hub miRNA in stage I and stage I-IV gastric cancer were gradually pushed to the upstream of QCR layers, 41-81 (beige and red bars) by additional quantum energy, 0-40 QCR of $H$. pylori infection (blue bars). The data clearly suggest that quantum energy level in gastric cancer was increased by a dopant factor of $H$. pylori infection, and oesophageal cancer was not at all. Thus, gastric cancer biomarker miRNAs might have been associated to some panel miRNAs in $H$. pylori infection as the dopant donor when compared with oesophageal cancer. Finally, the hub miRNA layer was selected from the total layer through the cluster of protein/protein interactions as described previously (Figures 2-4) [25].

\section{H. pylori infection and cancer}

$H$. pylori is a Gram-negative bacterium and colonizes on the gastric mucosa, and it is believed that $H$. pylori infection directly or indirectly contributes to gastritis and gastric cancer development [26]. The
cagA gene is presented in approximate $60 \%$ of $H$. pylori strains and the cagA encodes a $120-140 \mathrm{kDa}$ CagA protein. $H$. pylori could inject CagA protein into the host epithelium via the type IV secretion system, which induces morphologic alteration of the host cells. CagA protein antibody-positive patients infected with $H$. pylori have shown 5.8fold higher risk than uninfected people to develop gastric cancer [27]; however, CagA negative ones with $H$. pylori has also been 2.2-fold risk compared with uninfected control. Therefore, it is not clear whether $\mathrm{CagA}$ is absolute virulence factor for gastric cancer development or not. In addition, the purified VacA protein of $H$. pylori also had little effect on the viability of gastric epithelial cells [28].

In H. pylori infection miRNA biomarkers were selected as follows; upregulation of miR-28-3p, miR-143-3p, miR-151a-3p, miR-148a-3p and miR-223-5p in plasma specimens $[10,20]$. An infectious virulence factor, $H$. pylori CagA induced miR-223-3p expression [29]. Involving in pre-miRNA of miR-223, miR-223-5p has also been increased in both $H$. pylori-infected normal fixed tissues and fixed cancer ones of the human stomach [30], however, miR-223-5p was a tumor suppressor in lung cancer, colon cancer, breast cancer and oesophageal cancer cells [31-33]. Oncomir expression was not changed by $H$. pylori eradication in gastric cancer tissues when the $H$. pylori negative and positive ones were compared, whereas miR-223-5p was decreased and let-7 was increased by $H$. pylori eradication [34]. Further, miR-223-5p suppressed inflammatory pathway in $H$. pylori-infected macrophages [35]. The data suggested that the implication among H. pylori CagA and miR-223 may be anti-tumour and anti-inflammation. Although the specific miRNA panel have been identified in $H$. pylori-infected patients' plasma $[10,20]$ and $H$. pylori-positive patients' tissue of gastric cancer [36], gastric cancer progression has been also clinically reported to be implicated in H. pylori infection [37,38]. Wang et al. [39] showed difference of the miRNA expression profile between $H$. pylori-positive and $H$. pylori-negative groups in tissues fixed and cultured cells of gastric cancer. miR-143-3p significantly increased in $H$. pylori-positive tissue samples and RAC-alpha serine/threonine-protein kinase (AKT) expression was reduced by $\mathrm{miR}-143-3 \mathrm{p}$ in gastric cancer cells, that is similar with a diagnostic panel of miRNA upon $H$. pylori infection [20]. As shown in Figure 2 (the total layer) and 3A (the miRNA hub), miRNA-143-3p upregulation suppressed AKT2 with miR-124-3p and miR-184 in $H$. pylori infection. On the contrary, AKT activation is reviewed by $H$. pylori-induced chronic gastritis [38] and activation of AKT was described in early gastric cancer tissues fixed [40,41]. Further, phosphorylation of AKT was increased by $H$. pylori infection and Pololike kinase 1 (PLK1) expression was significantly high, which would be related with the downstream of PI3K/AKT pathway. However, AKT2 suppression by miR-143-3p upregulation in the bona fide plasma might be involved in $H$. pylori-infectious gastric epithelial cells. Although AKT is oncogene in general [42], our data suggested that host cell reaction would be anti-tumour by $H$. pylori infection.

AKT has AKT1 and AKT2 isoforms, and two isoforms have different biological functions, and both AKT1 and AKT2 amplifications were observed in gastric cancer and hepatocellular or colorectal cancers, respectively $[43,44]$. But AKT2 is specifically implicated in glucose metabolism and in the upstream of insulin-like growth factor 1 receptor (IGF1R) [45], which was suppressed by upregulation of miR223-5p with let-7b-5p, let-7c-5p, let-7e-5p, miR-122-5p, miR-4458 and miR-7-5p (Figure 3A). It is well known that insulin-like growth factor 1 (IGF1) and IGF2 bind to IGF1R and IGF1R as a tyrosine kinase triggers phosphorylation of insulin receptor substrates (IRS-1 to -4) and Srchomology collagen (Shc), and then their signaling permits downstream mitogen-activated protein kinase (MAPK) and phosphatidylinositol 
Fujii YR (2019) Quantum microRNA network analysis in gastric and esophageal cancers: Xenotropic plant microRNAs cure from cancerous paradox via Helicobacter pylori infection

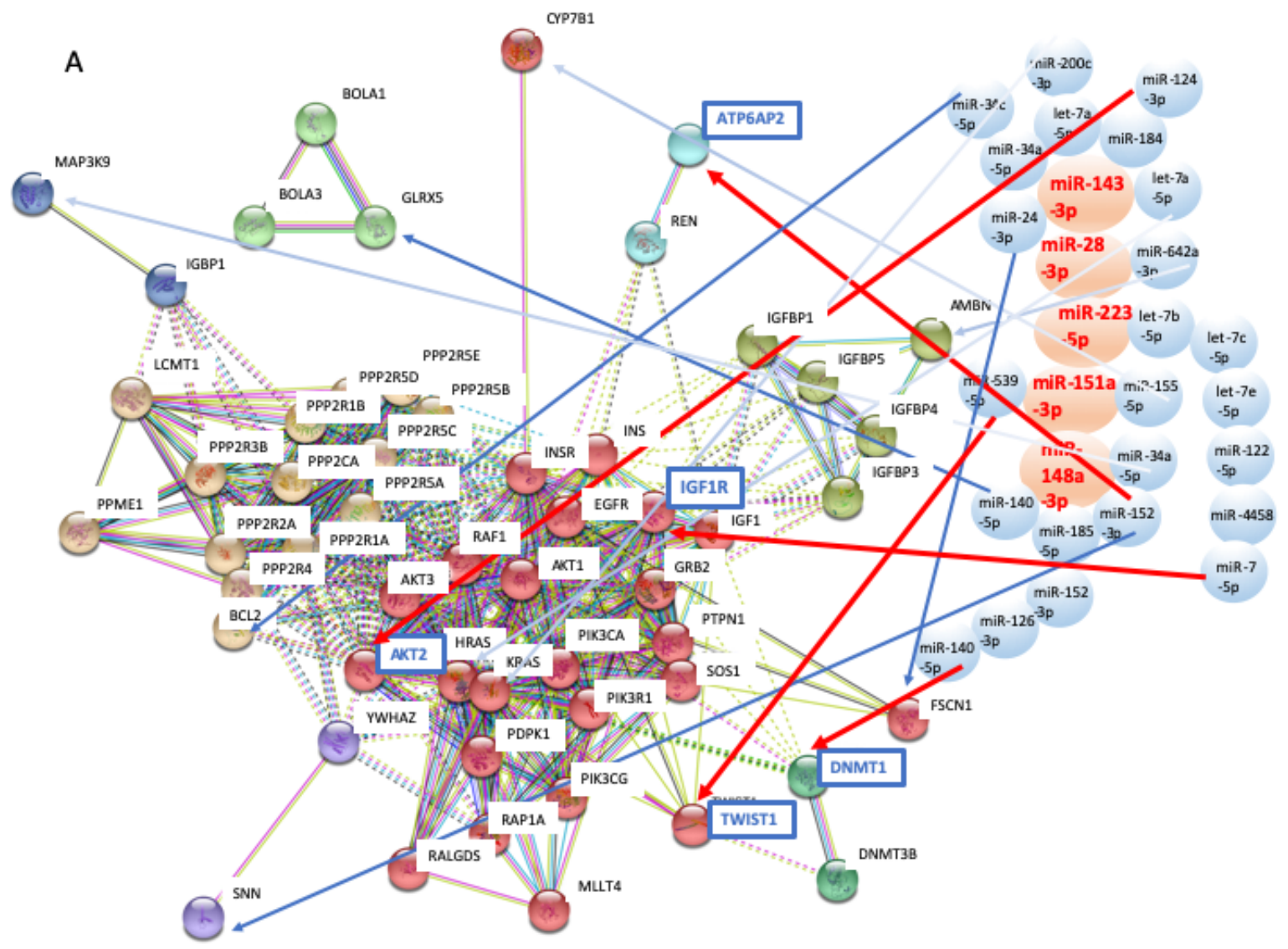

B

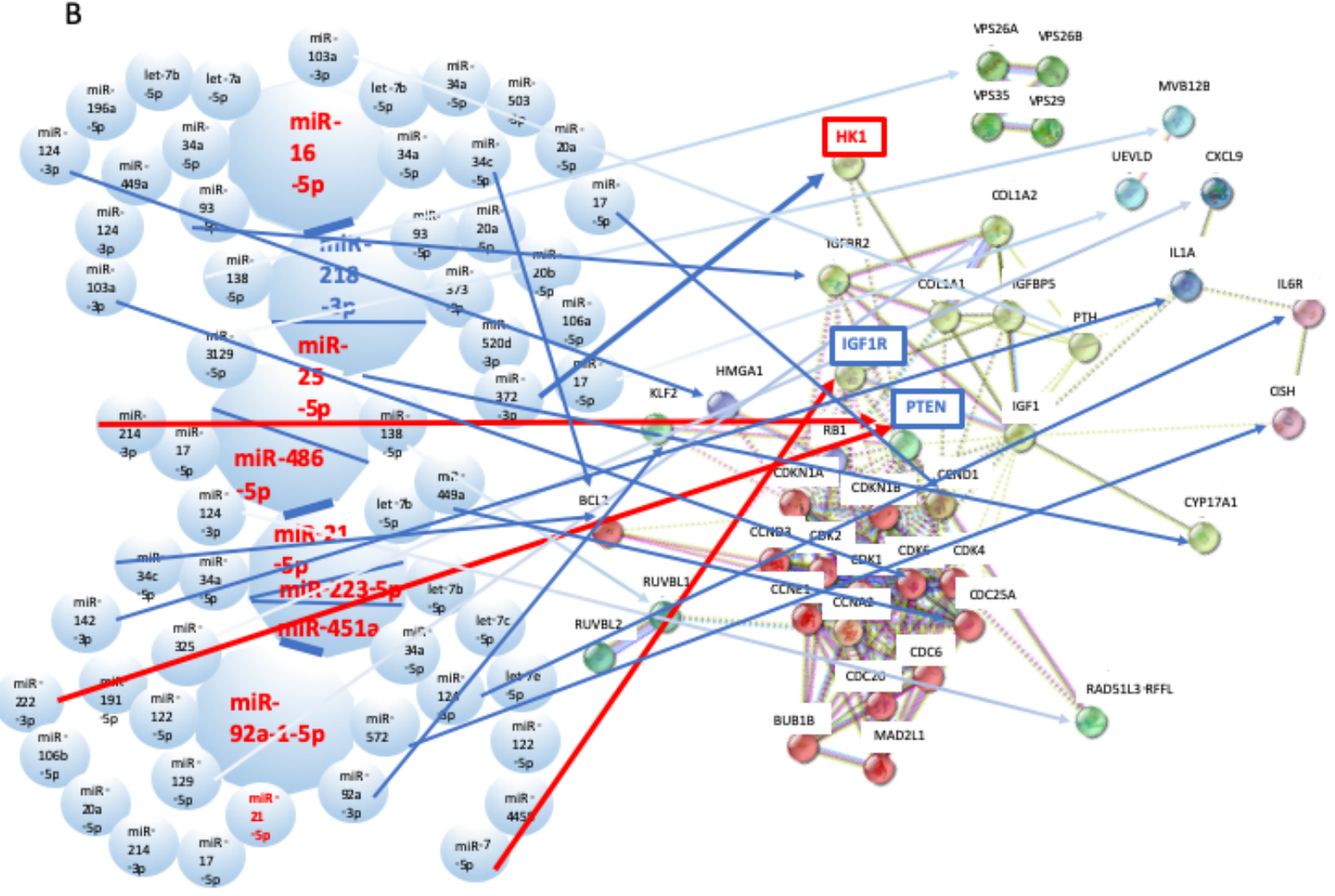


Fujii YR (2019) Quantum microRNA network analysis in gastric and esophageal cancers: Xenotropic plant microRNAs cure from cancerous paradox via Helicobacter pylori infection

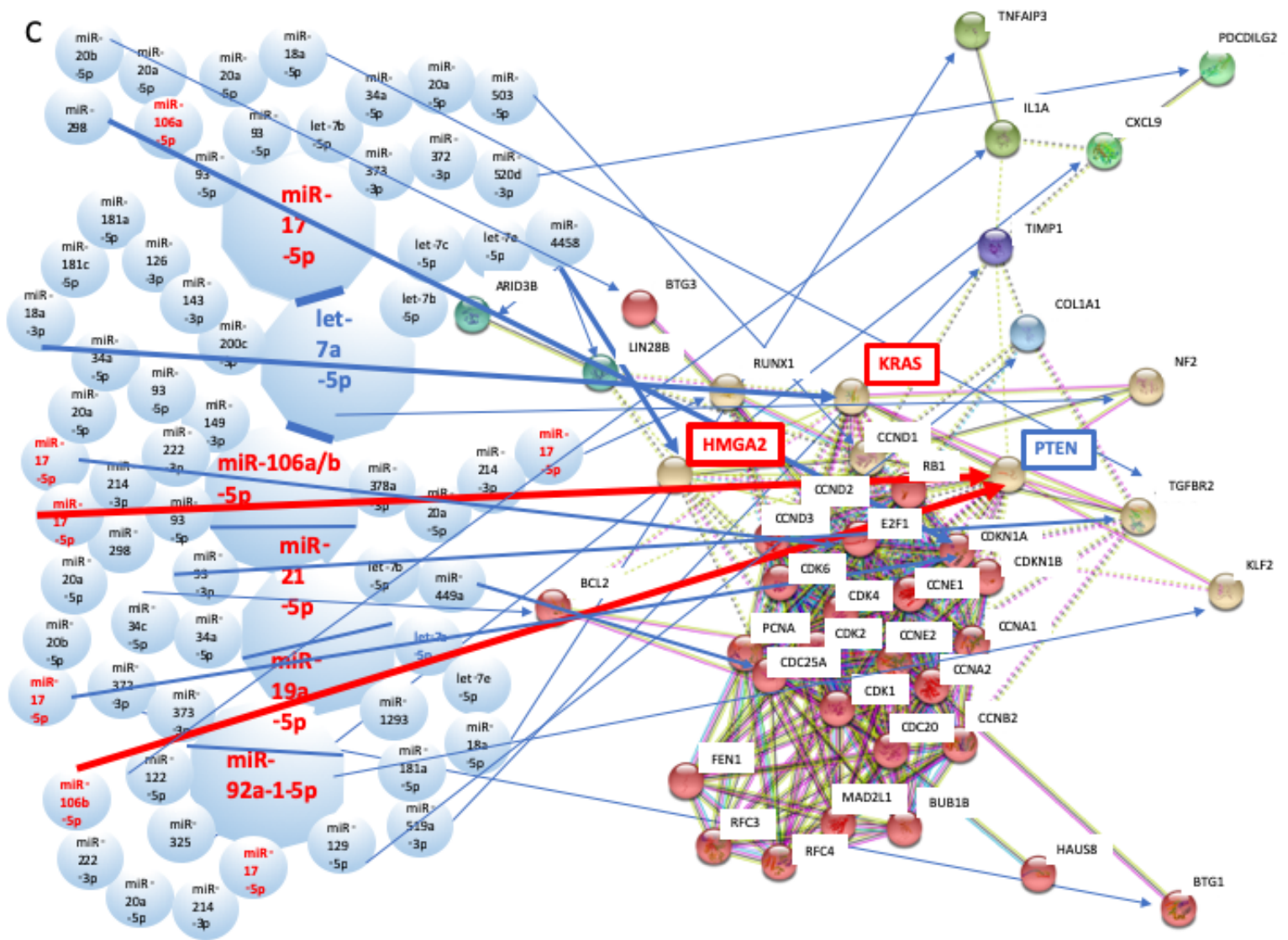

Figure 2. METS simulation of gastric cancer and $H$. pylori infection in all QCRs. After data mining, miRNA biomarker panels were selected and METS simulation was performed in $H$. pylori infection (A), gastric cancer in the stage I (B) and gastric cancer in the stage I-IV (C) on all QCRs. miRNAs: upregulation, red; downregulation, blue. Proteins: augmentation, red; suppression, blue.

A

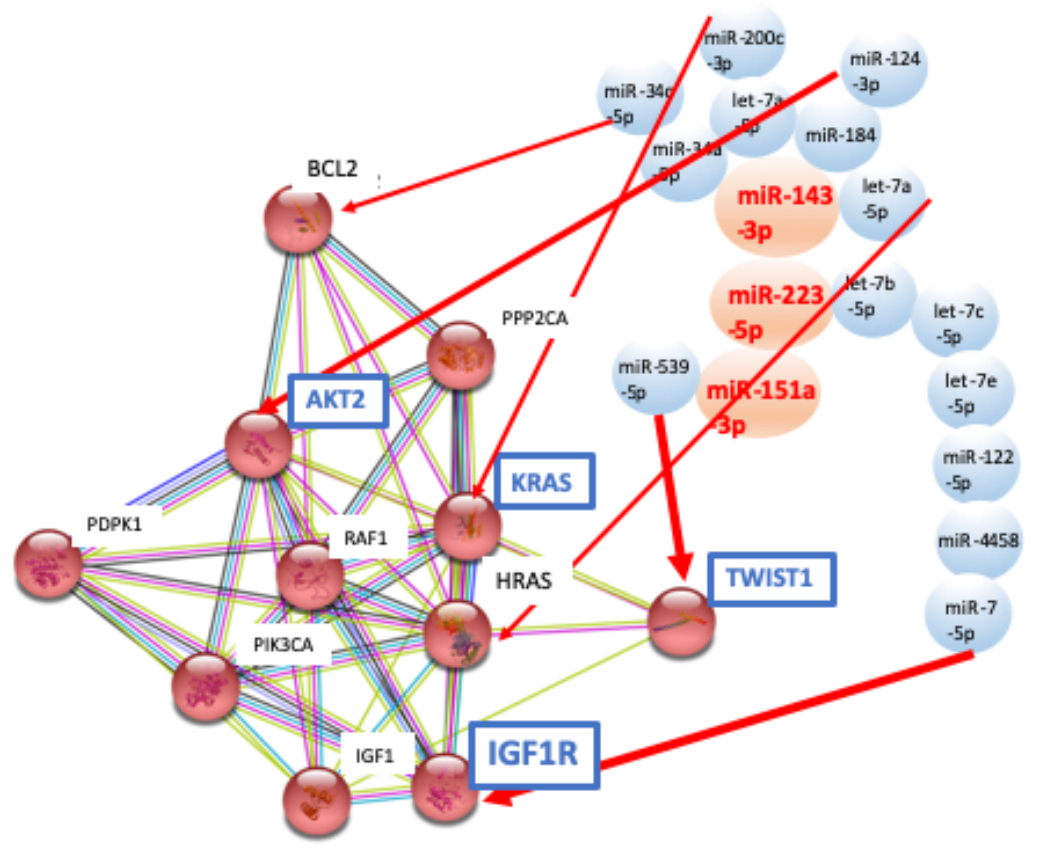


Fujii YR (2019) Quantum microRNA network analysis in gastric and esophageal cancers: Xenotropic plant microRNAs cure from cancerous paradox via Helicobacter pylori infection
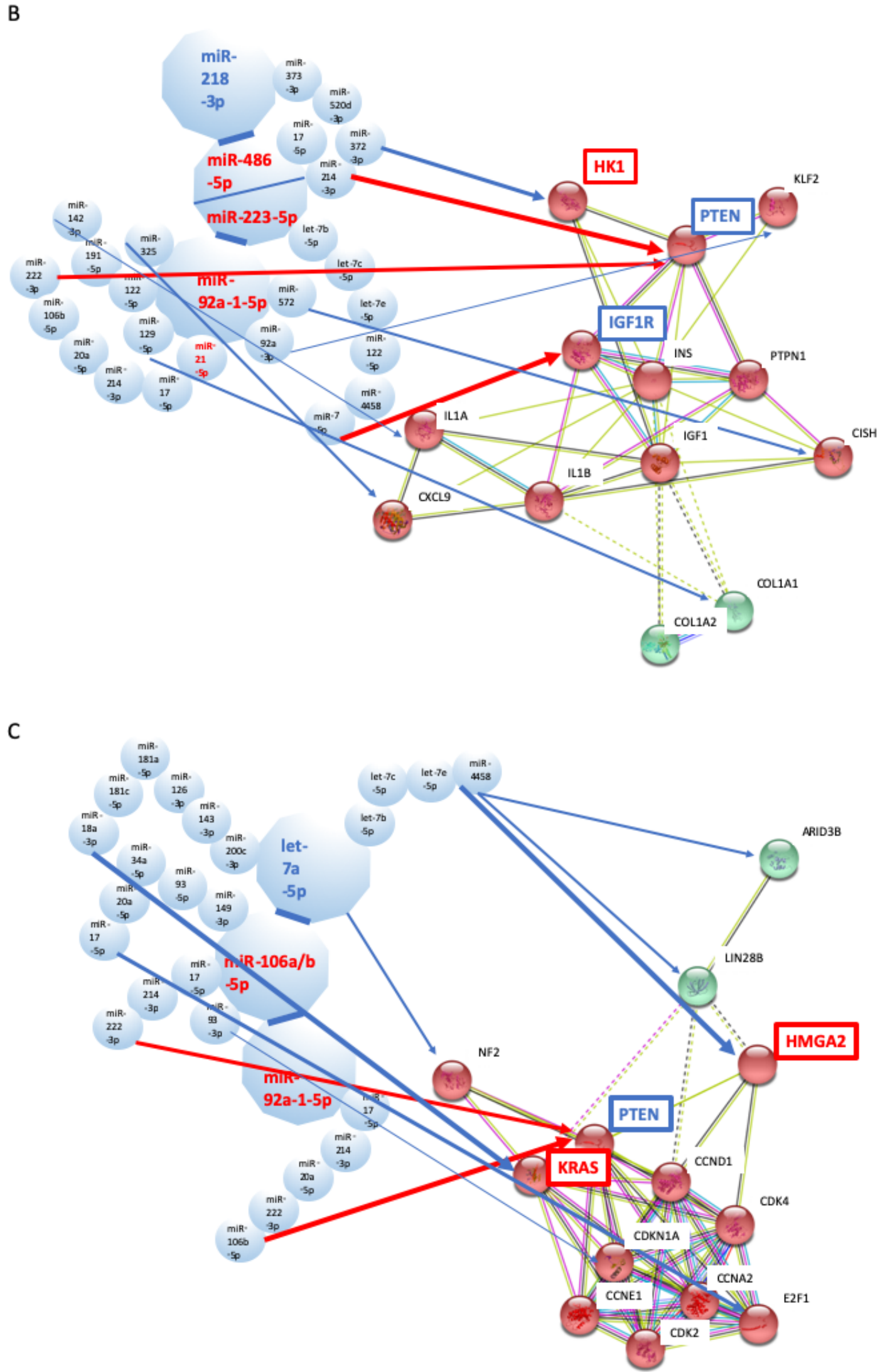

Figure 3. METS simulation of gastric cancer and $H$. pylori infection by the miRNA hub. The hub miRNAs were searched from all QCR METS simulation in Figure 2. The miRNA hub was determined by the cluster of protein/protein interaction, and then METS simulation was re-performed in $H$. pylori infection (A), gastric cancer in the stage I (B) and gastric cancer in the stage I-IV (C). miRNAs: upregulation, red; downregulation, blue. Proteins: augmentation, red; suppression, blue. 
Fujii YR (2019) Quantum microRNA network analysis in gastric and esophageal cancers: Xenotropic plant microRNAs cure from cancerous paradox via Helicobacter pylori infection
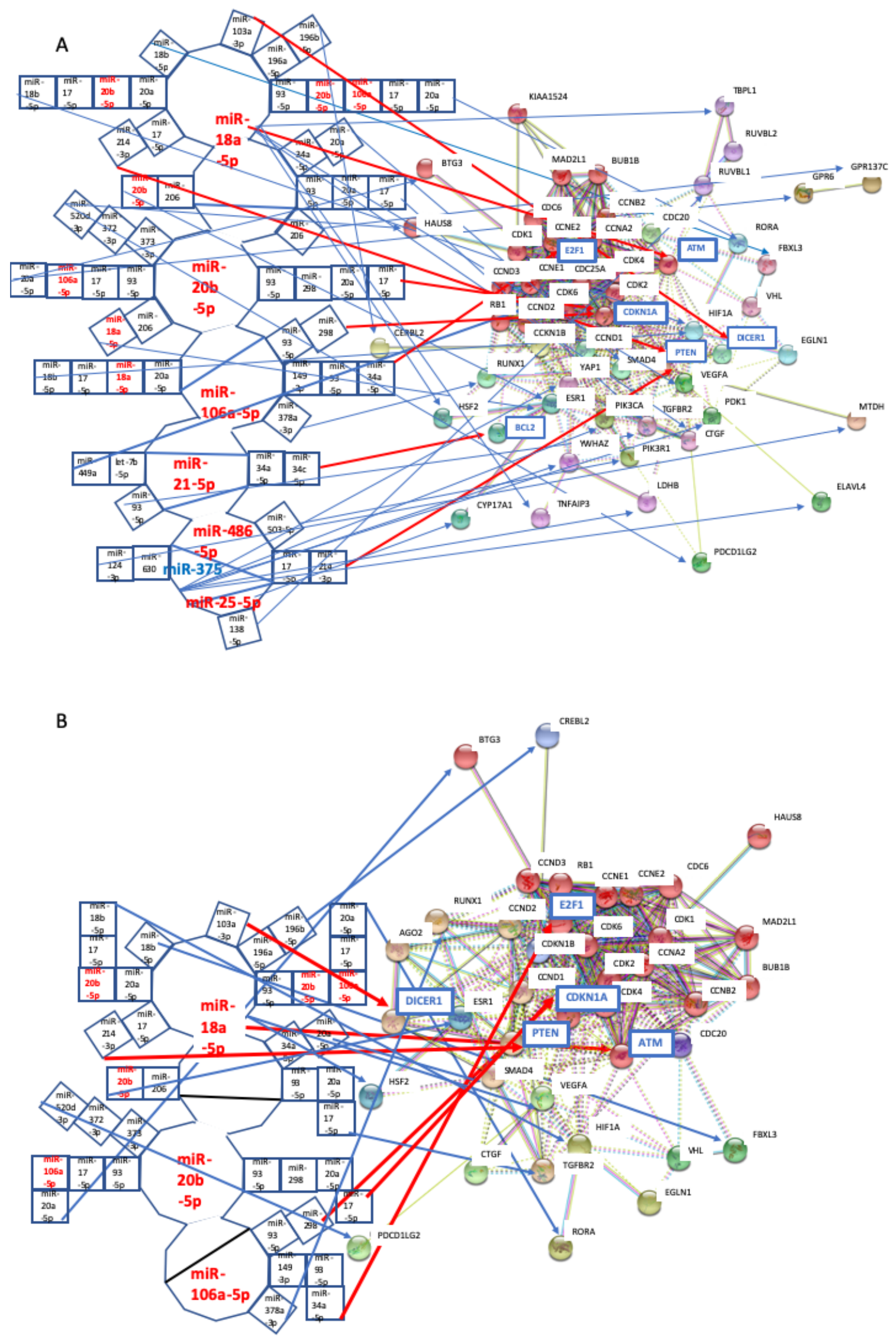
Fujii YR (2019) Quantum microRNA network analysis in gastric and esophageal cancers: Xenotropic plant microRNAs cure from cancerous paradox via Helicobacter pylori infection

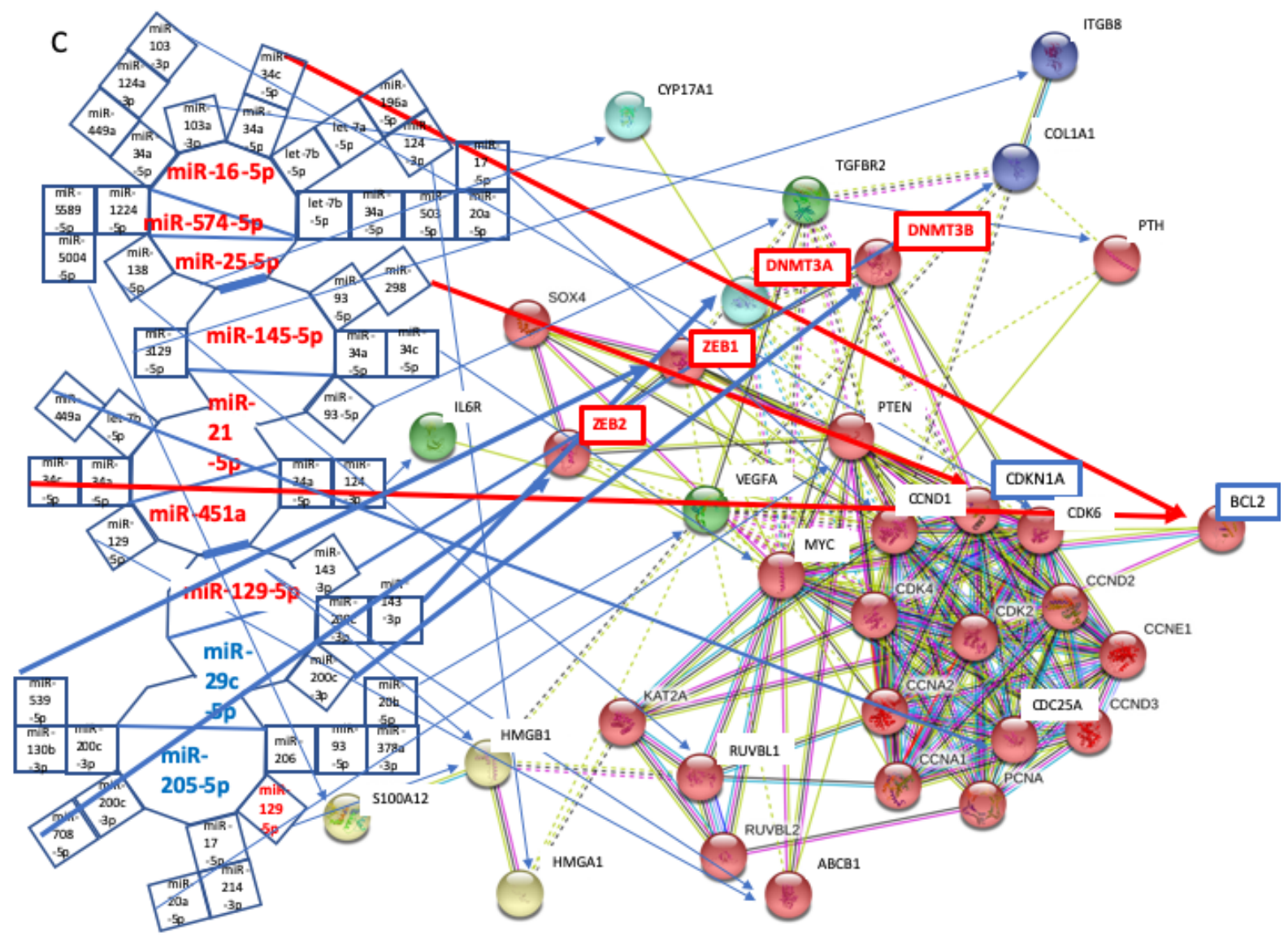

D

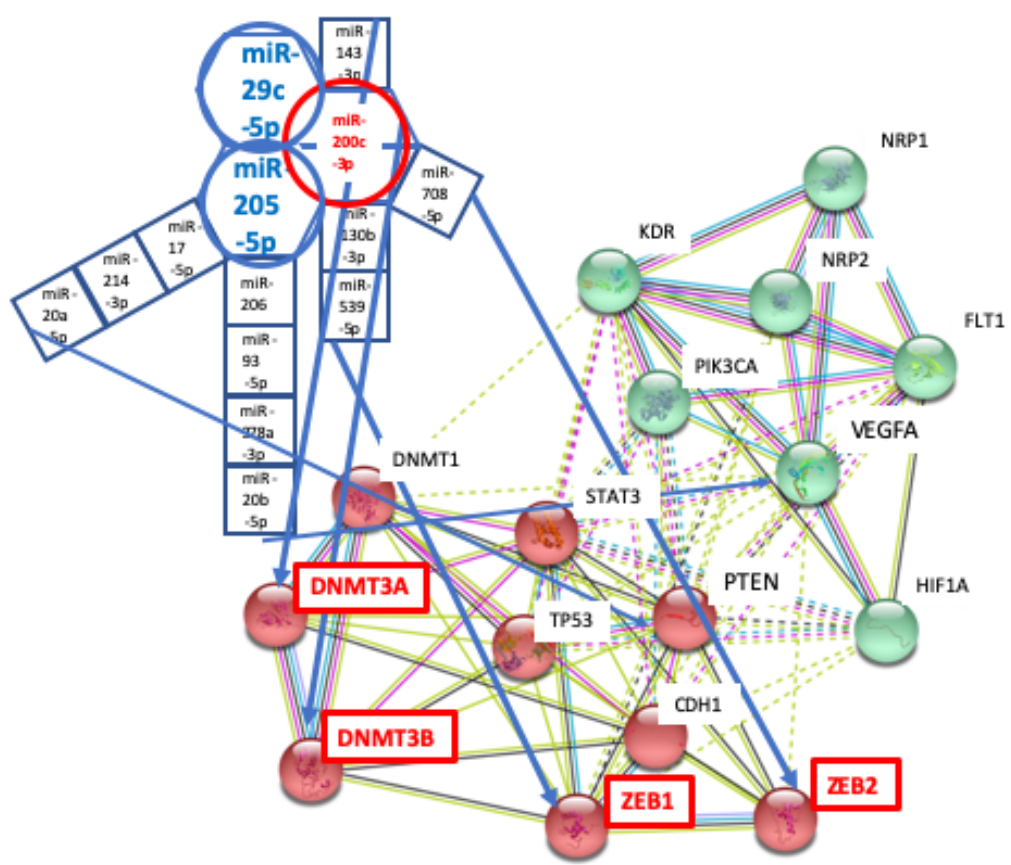

Figure 4. METS simulation of ESCC. The results of METS simulation were represented as (A) ESCC in the stage of 0-I of all QCRs, (B) ESCC in the stage of 0-I of the miRNA hub, (C) ESCC in the stage of I-IV of all QCRs and (D) ESCC in the stage of I-IV of the miRNA hub. miRNAs: upregulation, red; downregulation, blue. Proteins: augmentation, red; suppression, blue. 

pylori infection

3-kinase (PI3K)/AKT to activate [46]. Therefore, Inhibition of IGF1R induces suppression of AKT under the signal transduction pathways. Thus, at least, $H$. pylori infection may rationally be explained by reduction for the possibility of oncogenesis.

Although basic helix-loop-helix transcription factor 38 (TWIST1) expression high was implicated in positive proliferation of gastric cancer cell [47] and DNA methyltransferase 1 (DNMT1) expression was higher in gastric cancer than normal, para-cancerous and dysplasia tissues in the bioinformatic meta-analysis [48]. TWIST expression was suppressed by miR-151a-3p upregulation with miR-539-5p (Figure 2A and $3 \mathrm{~A}$ ) and DNMT1 is also blocked by miR-148a-3p upregulation with miR-185-5p, miR-152-3p, miR-126-3p and miR-140-5p (Figure 2A). miR-148a-5p was downregulated in gastric cancer and miR148a-5p suppressed DNMT1 in gastric cancer cells [49], in contrast, DNMT1 was overexpressed in gastric cancer and hypermethylation of DNA by DNMT overexpression reduced expression of miR-148a-5p [50]. Subsequently, $H$. pylori infection was predicted as non-oncogenic because of downregulation of DNMT1 and TWIST1 as above described in AKT2/IGF1R pathway.

Further, ATPase $\mathrm{H}+$ transporting accessory protein 2 (ATP6AP2) was downregulated by upregulation of miR-148a-3p with miR-152-3p (Figure 2A) and ATP6AP2/renin receptor expression was decreased in H. pylori-infected gastric biopsies of gastritis [51]. Functional loss of ATP6AP2 induced to be pathognomonic for tumour in granular cells [52]. Although granular cell tumour is rare neoplasm to exhibit nonaggressive behaviour, relation between proton pump and ATP6AP2 may have some responsible for development of gastritis because ATP6AP2 is a subunit of v-H+ ATPase and it is essential for v-H+ ATPase to canonically function as a proton pump through plasma membrane [53]; however, the decrease in the stomach by proton pump inhibitor reduces the infiltration of $H$. pylori [54]. Furthermore, after H. pylori eradication successfully, long-term proton pump inhibitor users increased the risk of gastric cancer [55]. The data suggested that $\mathrm{v}-\mathrm{H}+$ ATPase inhibition would be pathogenic but not oncogenic. On the contrary, another $\mathrm{V}_{1}$ A subunit of $\mathrm{v}-\mathrm{H}+\mathrm{ATPase}$ was $76 \%$ positive in gastric cancer tissues and siRNA of $\mathrm{V}_{1} \mathrm{~A}$ inhibited proliferation of gastric cancer cells [56]. v-H+ ATPase subunits would be a target of several cancers involving in gastric and oesophageal cancers [57]; however, there is some possibility that subunit inhibitor or proton pump inhibitor is not directly a proton pump inhibitor in vivo [58]. The pharmaceutical effects of subunit inhibitor should be evaluated by the miRNA expression profile under the treatment of subunit inhibiting agents [25]. These evidences strongly support that pathogenicity of $H$. pylori infection may be pre-oncogenic in the quantum network of miRNA/mRNA genes via proton pump inhibition during long-term under the presence of oncogenic CagA and sRNA products of $H$. pylori $[59,60]$.

Although the network analysis of gastric cancer has been performed with and without $H$. pylori using The Cancer Genome Atlas (TCGA) database, the results of the analysis were limited by the small sample size of TCGA. PI3K/AKT pathway inhibition was found as effects of oncoprotein CagA [61]. However, the same PI3K/AKT pathway was implicated in gastric cancer by the network analysis of miRNA/mRNA using TCGA data without $H$. pylori connection [62]. It would be due to approximate $90 \%$ of $H$. pylori infectious rate $[26,63]$, but approximately only $1-3 \%$ of people infected were developed to gastric cancer [64]. In a most recent report by Bayesian meta-analysis provided an accurate interpretation of randomized evidence, the preventive effectiveness of eradication in $H$. pylori has been resulted as an insufficient evidence to support or refute that for therapy in gastric cancer [65]. In previous meta-analysis, eradication therapy of $H$. pylori prevented gastric cancer [66]; however, most of data was calculated by the risk ratio [67]. In the case of the risk difference (absolute risk) in meta-analysis, the effectiveness of $H$. pylori eradication therapy was not statistically significant [68]. Since it has been remained whether $H$. pylori is still a friend or a foe [69], the outcome remains dubious. Therefore, the MMP of miRNA including the common miRNA markers between $H$. pylori infection and gastric cancer was further investigated by quantum network analysis.

\section{Gastric cancer}

In 2018 new gastric cancer incidence around world was $1,033,701$ on the fourth ranking and death cases were 782, 685 on the third ranking (gco.iarc.fr/today/data/factsheets/cancers/7-Stomach-factsheet.pdf). Compared with other cancers, the incidence and mortality rates have been recently reduced; however, gastric cancer has still been a mortal disease depending on the lifestyle. More than $70 \%$ of gastric cancer occur in the developing areas in East Africa, East Asia, and parts of Central and South America. It is due to poor hygiene and higher $H$. pylori prevalence rates. $H$. pylori is the class I carcinogen of gastric cancer classified by the International Agency for Research on Cancer (IARC) of the World Health Organization (WHO). Reduction of risk factors in gastric cancer, such as $H$. pylori eradication, improved hygiene, food preservation, fall in smoking, etc. has decreased cancer incidence; however, 5-year survival rates was $25 \%$ in period 2005-2007 by EUROCARE-5 (eurocare.it) [70]. The problem is the late diagnosis because of asymptomatic or else unspecified in early gastric cancer. Most gastric cancers are advanced at detection while endoscopy in dyspepsia was recommended at age over 45 years [71] and gastric cancer has a poor prognosis. Therefore, non-invasive diagnose marker is critical for reduction of 5-year survival.

Classical standard biomarkers, CEA, CA19-9 and their combination have applied for gastric cancer, however, they were quite low sensitivity and specificity [72]. Epigenetic alteration, hypermethylation of SOX 17 has been shown to diagnose in early gastric cancer [73] and hypermethylation was found in $H$. pylori-related gastric cancer [74]. DNA methylation was gradually decreased in $H$. pylori-infected gastritis independent of CagA status, therefore, hypomethylation has a problem about specificity between $H$. pylori-related gastritis and gastric cancer. Further, Sox17 hypermethylation would not succeed to diagnostic distinguish between gastritis and gastric cancer with or without $H$. pylori infection at all.

After data mining, in the stage I of GC, upregulation of miR-215p, miR-223-5p, miR-16-5p, miR-25-5p, miR-92a-1-5p, miR-451a and miR-486-5p, and downregulation of miR-218-1-3p were selected as biomarkers in plasma specimens $[10,11]$. In the case of stage I-IV (I: 23.8\%, II: $21.2 \%$, III: $43.5 \%$, IV: $11.1 \%$, unknown: $0.4 \%$ ), upregulation of miR-17-5p, miR-106a/b-5p, miR-21-5p, miR-19a-5p, and miR-92a$1-5 p$, and downregulation of let-7a-5p were selected as biomarkers in plasma specimens $[12,13]$. Since the aetiology differences of human disease were identified by the combination of miRNAs into MMP as described previously [9], if the same target in different miRNA combinations is selected between $H$. pylori infection and gastric cancer, the infection by $H$. pylori may be involved in gastric cancer. To elucidate gastric cancer induction by $H$. pylori, commonly etiologic factors among infection and carcinogenesis were investigated by computer prediction with quantum network analysis in early stage of gastric cancer. Although expression of IGF1R were downregulated by 
upregulation of the common miR-223-5p combination of let-7b-5p, let-7c-5p, let-7c-5p, miR-122-5p in Figure 2B (the total layer) and 3B (the miRNA hub), miR-4458 and miR-7-5p, and AKT connection in $H$. pylori infection was not involved in stage I gastric cancer (Figure $2 \mathrm{~A}$ and 2B). The common miRNA/target connection on IGF1R protein was found in the miRNA hub of quantum network of stage I gastric cancer (Figure 3A and 3B); therefore, $H$. pylori could affect miRNA expression in the early gastric cancer. On the contrary, enforced expression of phosphatase and Tensin homolog (PTEN) resulted in decreasing of IGF1R expression upon gastric adenocarcinoma cells [75]; however, tumor suppressor PTEN was strongly blocked by both upregulation of miR-486-5p with miR-17-5p and miR-214-3p, and upregulation of miR-92a-1-5p plus miR-21-5p with miR-17-5p, miR-214-3p, miR20a-5p, miR-106b-5p and miR-222-3p (Figure 2B and 3B). PTEN expression is low in gastric cancer [76] and the downregulation of PTEN is implicated in induction [77], maintenance of a malignant state [78], and progression and metastasis of gastric cancer [79]. These data were strongly supported by our in silico simulation that in the stage I-IV, PTEN was strongly repressed by upregulation of miR-106a/b-5p with miR-17-5p, miR-93-5p and miR-298, and upregulation of miR92a-1-5p with miR-17-5p, miR-106b-5p, miR-214-3p, miR-20a-5p and miR-222-3p in Figure 2C (the total layer) and 3C (the miRNA hub).

In the stage I-IV, miR-21-5p was upregulated in the total layer of gastric cancer (Figure $2 \mathrm{~B}$ and $2 \mathrm{C}$ ). miR-21-5p and miR-222-5p were upregulated in the plasma of gastric cancer [80], and high expression of miR-21-5p and miR-222-3p in the fixed tissues was related to poor survival of gastric cancer [81]. Further, in the stage I-IV, miR-17/92 cluster was upregulated in the total layer of gastric cancer (Figure $2 \mathrm{~B}$ and $2 \mathrm{C}$ ). miR-17/92 cluster including miR-17-5p, miR-92a-1-5p, miR$20 \mathrm{a}-5 \mathrm{p}, \mathrm{miR}-106 \mathrm{a} / \mathrm{b}$ was increased in the plasma of gastric cancer and was associated with the progression of gastric cancer $[82,83]$. On the other hand, downregulation of let-7a-5p upregulated KRAS and HMGA2 with miR-200c-5p, miR-143-3p, miR-126-3p, miR-181a-5p, miR-181c-5p and miR-18a-3p, and with let-7b-5p, let-7c-5p, let-7e$5 p$ and miR-4458, respectively (Figure $2 \mathrm{C}$ and $3 \mathrm{C}$ ). Although KRAS mutation and amplification were found in $5 \%$ and $7 \%$ of gastric cancer in the data of TCGA [84], H. pylori-infected patients with KRAS mutation contained only $0.5-0.2 \%$ of gastric cancer, and there was no correlation between $H$. pylori infection and KRAS mutation in gastric cancer $[85,86]$ and KRAS mutation was not associated with histological progression of gastric cancer with $H$. pylori [87]. Therefore, it has still not been cleared in the aetiology of KRAS activation upon gastric cancer; however, transactivation of KRAS via ZNF312b was increasing human gastric tumour progression in nude mouse [88]. Our quantum prediction shows a novel insight that KRAS upregulation by downregulation of let-7a-5p combination would maintain gastric cancer progression without mutation and amplification of KRAS gene. let-7a-5p was significantly downregulated in gastric cancer specimens and inhibited its proliferation [89]. The proliferation of gastric cancer cells has been inhibited by Chinese herbal medicine, Yangzheng Sanjie decoction through upregulation of let-7a-5p [90]. Furthermore, overexpression of HMGA2 was also associated with poor prognosis of gastric cancer in a meta-analysis [91,92]. Oncogenic KRAS expression induced HMGA2 [93], and RUNX/TP53 negative gastric epithelial cells induced spontaneous EMT under upregulation of HMGA2 by the EGFR/RAS pathway [94]. Thus, upregulation of KRAS and HMGA2 by downregulation of let-7a-5p might be implicated in gastric cancer progression among stage I to IV and the etiologic characters of gastric cancer are highly distinct from those of $H$. pylori infection except for IGF1R downregulation.
Hexokinase 1 (HK1) was upregulated by downregulation of miR218-3p with miR-93-5p, miR-373-3p, miR-520d-3p and miR-372-3p (Figure 2B and $3 \mathrm{~B}$ ). HK1 was overexpressed in gastric cancer tissues, and overexpression of HK1 was associated with lymphatic metastasis and clinical staging in gastric cancer [95]. Warburg effect (aerobic glycolysis) including HK1 activation contributes to tumorigenesis [96]. IGF1R inhibition is the common tuning between $H$. pylori infection and early gastric cancer, and inhibition of IGF1R expression would induce high susceptibility to glucose transporting via insulin receptor (INSR) $[97,98]$ because of $87-97 \%$ presence of INSR in gastric cancer [99]. Stress, such as mal-foods or urease of $H$. pylori mutated $\Delta \mathrm{CagA}$ directly induced hypoxia-induced factor (HIF) [100] and hypoxia promotes gastric cancer malignancy via HIF activation [101]. Further, hypoxia suppressed let-7a in hypoxic human tumour cells [102] and downregulated let-7 family in rat cardiac fibroblast [103]. Warburg effect and hypoxia by stress of $H$. pylori infection were associated with cancer, and its chemotherapy and radiation resistances [104,105]. As shown in Figure 3, these evidences suggested that $H$. pylori infection would additionally contribute to progression of malignancy in gastric cancer cells via glucose metabolic pathway on a paradox in Zen Buddhism riddle, called 'Koan' with direct tumour initiation upon host condition by suppression of PTEN, and via KRAS conversion from downregulation to upregulation (Figure 3A and 3C). The discrepancy between statistic meta-data between significant of the risk ratio and no significant of the absolute risk may be due to the paradoxical effect of $H$. pylori infection for gastric cancer. This early process would be followed by PTEN/KRS/HMGA2 protein hub for further progression of metastatic gastric cancer. Therefore, in Figure 3, it is easily understood with the common miR-223-5p/IGF1R connection that even though people who infected with $H$. pylori, stress would rarely induce tumorigenic malignancy in the stomach, which was supported by low incidence of gastric cancer in high infectious rate of $H$. pylori [64].

\section{Esophageal cancer}

H. pylori infection has been observed by upper gastrointestinal endoscopic biopsy and esophagectomy, and there was a negative association between $H$. pylori infection and a reduced risk of ESCC [5]. Other reports have also showed significantly no correlation between $H$. pylori infection and ESCC risk by a meta-analysis [106-108]. Therefore, ESCC cases are a control of $H$. pylori infection-positive in the etiological relation of cancer.

Oesophageal cancer has two pathological subtypes, one is oesophageal squamous cell carcinoma (ESCC) and the other is adenocarcinoma (AC). Oesophageal cancer is the $7^{\text {th }}$ leading cause of cancer-related death and ESCC is approximate $90 \%$ of oesophageal cancer cases in apart of Asia and Sub-Saharan Africa [109]. For diagnosis of oesophageal cancer invasive endoscopy and biopsy are the gold standard techniques even less symptomatic at early stage of oesophageal cancer. Non-invasive tumour markers, CEA, CA 19-9, CA125 and SCC were too low sensitivity to develop mass screening and were not correlated with stage of oesophageal cancer [110]. Therefore, the diagnosis of oesophageal cancer occurs late and 5 years survival rate is very low about $15-20 \%$ in US [111]; however, early stage diagnosis by endoscopy and surgical treatment increased 5 years survival rate as high as $85 \%$ [112]. Early and significant screening more is increasing survival rate and it is suggested that the prediction of cancer could prevent development of clinical symptom in disease from healthy individuals. 
In the stage 0 -I of ESCC, upregulation of miR-18a-5p, miR20b-5p, miR-106a-5p, miR-21-5p, miR-486-5p and miR-25-5p, and downregulation of miR-375 were observed as biomarkers in plasma specimens $[14,15]$. As shown in Figure $4 \mathrm{~A}$ (the total layer) and $4 \mathrm{~B}$ (the miRNA hub), ataxia telangiectasia mutated (ATM) was suppressed by upregulation of miR-18a-5p. ATM is serine/threonine kinase and is belong to the PI3/PI4 kinase family. DNA damage activates ATM and the activated ATM phosphorylates Chk1 and Chk2, then ATM stabilizes TP53 by phosphorylation. Both Chk1 and Chk2 are implicated in the G2/M cell cycle checkpoint, therefore, ATM is an influencer of repairing DNA damage before the mitosis [113,114]. Caffeine treatment inhibited ATM and it showed several of the phenotypic alteration in the cells [115]. Further, ATM mutation results centromeric instability and increasing of susceptibility to a variety of cancer $[116,117]$. Although Jaridonin inhibited proliferation of ESCC through G2/M arrest, Jaridonin activated ATM and arrested G2/M cell cycle, and ATM inhibition by caffeine reversed ATM activation in human ESCC [118]. These data suggested that ATM suppression by miR-18a-5p would be unstable DNA damage response and would progress carcinogenesis in oesophageal epithelial cells.

CDKN1A was inhibited by miR-20b-5p plus miR-93-5p, miR298, miR-20a-5p and miR-17-5p, and miR-106a-5p plus miR-93-5p and miR-298 (Figure 4A and 4B). miR-20b-5p and miR-106a-5p are localized as polycistronic genes into the cluster miR-106a/363 in the chromosome X [119]. Although miR-20b, miR-363-3p and miR-363$5 p$ in miR-106a/363 cluster showed an anti-proliferating effect on oral carcinoma [120], different combination of miR-106a-5p with miR20b-5p in miR-106/363 cluster would be oncogenic because the target of CDKN1A as a cyclin kinase (Cdk) inhibitor is a tumour suppressor and low concentrations of p21 (Cip1/Waf1/CDKN1A) promote proliferation of tumour cells [121]. Further, E2F1 was decreased by miR-106a-5p with miR-149-3p, miR-93-5p and miR-34a-5p (Figure $2 \mathrm{~A}$ and $2 \mathrm{~B}$ ). E2F1 is phosphorylated by ATM and Chk2 kinases in response to DNA damage, therefore, suppression of ATM expression would also E2F1 activation and low level of expression of E2F1 would maintain malignant state [122]. DICER suppression by miR-18a-5p plus miR103a-3p was predicted (Figure 4A and 4B), as described previously, decreasing of DICER expression was oncogenic on the stage zero of colorectal cancer [24]. miR-18a-5p with miR-17-5p and miR-214-3p inhibited tumour inhibitor PTEN expression (Figure 4A and 4B). The prediction is supported by the Sun's report [123] that $51.4 \%$ of ESCC tumours were negative of PTEN expression and PTEN expression in ESCC was statistically lower than non-tumour oesophageal epitheliums. HIF1A was inhibited by upregulation of miR-18a/b-5p, miR-20a/b-5p and miR-17-5p and BCL2 is blocked by upregulation of miR-21-5p plus miR-34a/c-5p (Figure $4 \mathrm{~A}$ ), however, expression of hypoxia-related target HIF1A was inversely associated with that of oncogene BCL2, which is related to the response of photodynamic therapy against early ESCC [124]. Therefore, expressions of HIF1A and BCL2 may be dependent on miRNA-17/92 cluster as well as the oxygen in early oesophageal cancer.

In the process of transition on the stage from I to IV (I-II: $36.6 \%$, III-IV: $63.4 \%$ ), downregulation of miR-29c-5p and miR-205-5p, and upregulation of miR-16-5p, miR-574-5p, miR-25-5p, miR-21-5p, miR-451a and miR-129-5p were detected as biomarkers in patient sera [16-19]. Although inverse correlation among levels of DNMT3A and DNMT3B and the expression of miR-29 was found in hepatocytes [125], downregulation of miR-29c-5p would enhance the DNMT3A and DNMT3B expressions in Figure 4C (the total layer) and 4D (the
miRNA hub). In cancer cells, generally, CpG rich regions including promoter of DNA are usually heavily methylated [126] and aberrant DNA methylation is implicated in ESCC progression [127]. Since DNA CpG methylation is contributed by DNMT3A and DNMT3B, a methylation signature of DNA was identified in ESCC patients with lymph node metastasis at statistically significant accuracy [128]. Therefore, hypermethylation of DNA would be involved in epithelial-mesenchymal transition (EMT). Further, ZEB1 high expression was related with the malignancy of various cancer and EMT [129]. The evidence supported our simulation that miR-29c-5p suppression augments expression of its targets ZEB1 and ZEB2, probably associated to upregulation of miR-200c-3p (Figure $4 \mathrm{C}$ and $4 \mathrm{D}$ ) because of increasing of miR-200c-3p in ESCC cell line [130] and tumour of patients [131].

As CDKN1A expression was blocked by miR-17/93 family in stage 0-I of ESCC (Figure 4A and B), upregulation of miR-145-5p with miR93-5p and miR-298 reduced expression of CDKN1A in stage I-IV (Figure 4C). Further, BCL2 was also inhibited by upregulation of miR21-5p and miR-16-5p with miR-34a-5p and miR-34c-5p (Figure 4C). However, miR-34a-5p was downregulated in ESCC cells $[132,133]$ and $\mathrm{miR}-34 \mathrm{a} / \mathrm{c}-5 \mathrm{p}$ were inactivated by $\mathrm{CpG}$ methylation in patients with ESCC $[134,135]$. Therefore, it is suggested that cell cycle may not be so essential for progression of oncogenesis in ESCC late stages because of suppression of cycling inhibitor CDKN1A and inhibition of oncogene BCL2, and there is no common etiologic factor between $H$. pylori infection and ESCC.

\section{Fresh vegetable and fruit diets to $H$. pylori infection in stomach}

As mentioned above, some people in Asia persistently infected with $H$. pylori do not suffer from high incident rates of gastric cancer by availability of fresh fruits and vegetables $[3,4]$. Since miRNAs of fruits and vegetables have been stably incorporated into the human circulating system and estimated in human tissues [9,136], the xenotropic miRNAs (xenomiRNAs) could affect the protein expression of tumour cells through tuning by the interaction between xenomiRNA and target mRNA $[9,137]$. Watermelon, Citrullus lanatus, is one of common fruits in Asia, and its plant miRNAs have been investigated in human plasma [138]. Six xenomiRNAs in watermelon juice were detected in the dynamic physiological pattern in human plasma at the absorption rate of 0.004 to $1.31 \%$. The top 5 of high absorbed xenomiRNAs, MIR157a, MIR156a, MIR172a, MIR168a and MIR162a were contained in apple fruit, and banana and tomato vegetables [139], which are also common food in Asia. The five plant miRNAs were homologically compared with human miRNAs, especially, on the sequences of the seed 8 nucleic acids in the 5' terminal region (Table 2). The seeds of MIR157a, MIR156a, MIR172a, MIR168a and MIR162a were $88,75,75,63$ and $75 \%$ homologous to those of miR-4520-3p, miR4644, miR-103a-2-5p, miR-4289 and miR-3125, respectively. Plant miRNAs could have similarly been functioned to human homologous miRNAs [9,137], therefore, the seeds of five human miRNAs were used for further analysis.

Protein targets of miR-4520-3p, miR-4644, miR-103a-2-5p, miR4289 and miR-3125 were investigated by miRNA target searching tools. The 3' untranslated regions (UTRs) of RHOA, SIX1 and DNMT1 had target sites of miR-4644 and miR-185-5p, and the 3'UTR of POTEE has the target site of miR-103a-2-5p (Data not shown). Since miR-4644 and miR-103a-2-5p would be functioned to MIR156a and MIR172a, respectively, the secondary structure of MIR156a and MIR172a to the target regions were computed by mfold and CentroidFold (Figure 5). 
Fujii YR (2019) Quantum microRNA network analysis in gastric and esophageal cancers: Xenotropic plant microRNAs cure from cancerous paradox via Helicobacter pylori infection

Table 2. Plant seed homology in human miRNAs

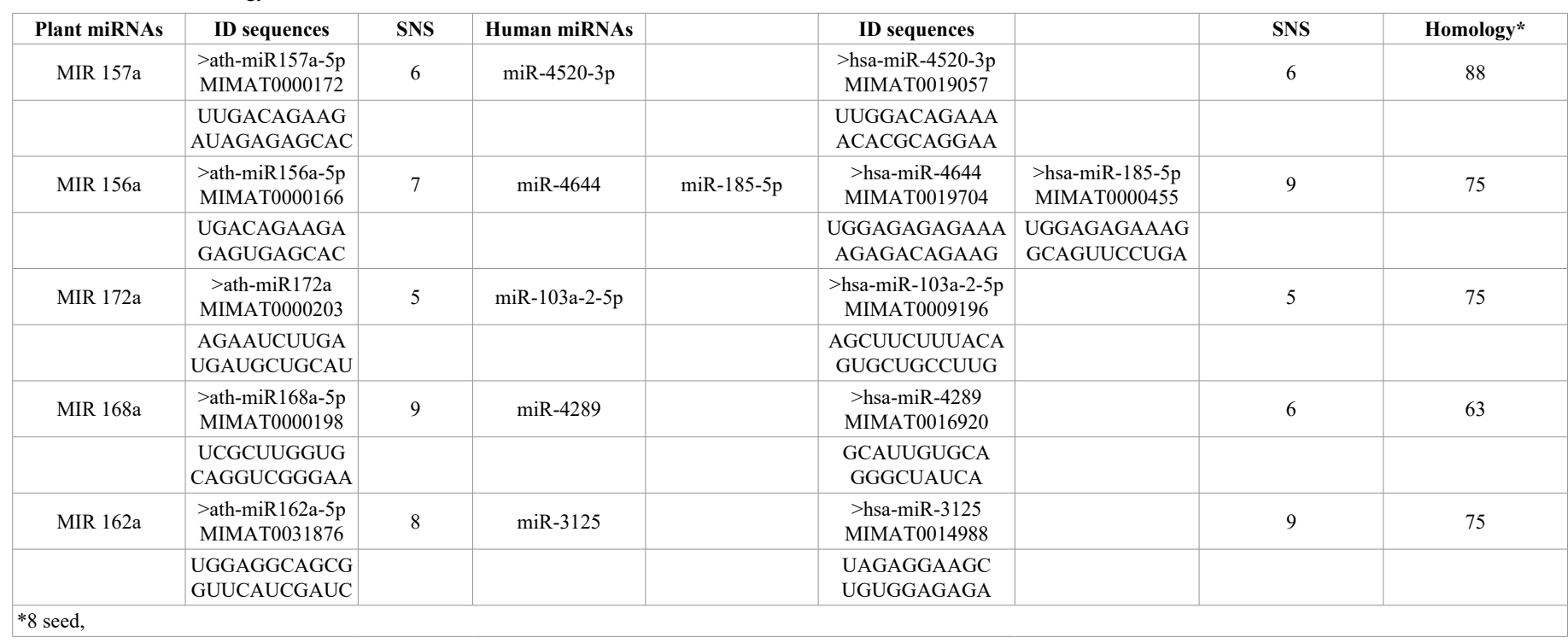

\begin{tabular}{ccc} 
Plant miRNAs & Targets & $\triangle \mathrm{G}$ \\
\hline MIR156a & RHOA & -4.8 \\
& SIX1 & -14.1 \\
& DNMT1 & -5.4 \\
MIR172a & POTEE & -4.5 \\
\hline
\end{tabular}

MIR156a ${ }_{\text {RHOA }}^{5^{\prime} \text { UGACAGAA }}{ }^{3^{\prime}}$
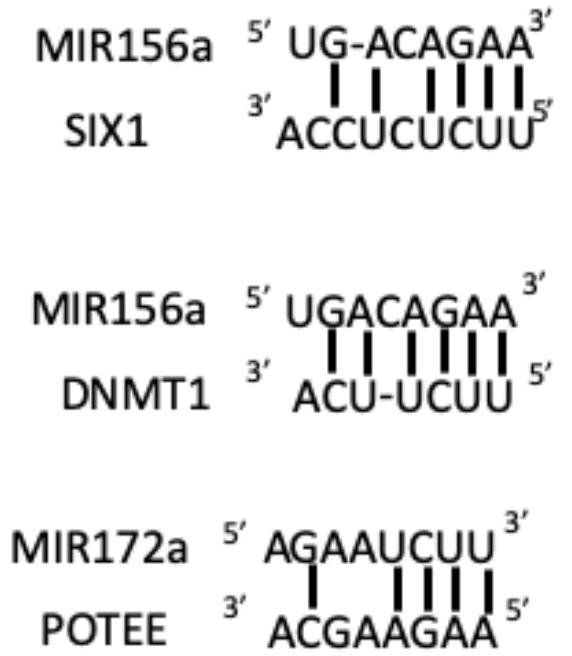

Figure 5. Investigation of protein mRNA 3' UTR against plant miRNAs. The target site specificity of plant miRNAs, MIR-156a and MIR-172a were searched in silico. The processes of the searching human protein targets against plant miRNAs were described in results and discussion. The free energy values $(\Delta G)$ were calculated between the sequences of the miRNA seed and 3'UTR (the upper table). The seed region of two plant miRNAs and protein 3'UTR target were paired (The lower picture).
To determine the target site specificity of xenomiRNAs, the free energy values $(\Delta \mathrm{G})$ were calculated. The $\Delta \mathrm{G}$ of MIR156a were $-4.8,-14.1$ and -5.4 to RHOA (3'UTR position of 92-98), SIX1 (3'UTR position of 196203) and DNMT1 (3'UTR position of 306-312), respectively. The $\Delta \mathrm{G}$ of MIR172a was -4.5 to POTEE (3'UTR position of 32-39). These data suggested that there would be possible target sites of plant xenomiRNA in human protein mRNA 3'UTR [9].

The quantum data of Watermelon was cohered to $H$. pylori infection quantum data. As shown in figure 6, protein phosphatase 2 subunits (PPP2Rs) protein/protein interaction in $H$. pylori infection was disappeared by watermelon feed. Although PPP2Rs were not directly tuned by the miRNA panel (Figure 2A), PPP2Rs were a tumour suppressor [140]. In vegetable (watermelon) quantum network, protein/protein interaction of PPP2Rs was rearranged to that of proteasome $\alpha$ and $\beta$ subunits (PSMA and PSMB) (Figure 6). PSMA and PSMB are subunits of the 20S proteasome core structure and members of peptidase family [141]. PSMA7 was upregulated in gastric cancer, however, PSMA 1-4 were downregulated [142]. Further, proteasome inhibitor, bortezomib was not effective for the advanced adenocarcinoma of the stomach in phase II clinical trial [143]. Proteasome subunit function may have not so important role to control gastric tumorigenesis.

On the contrary, RHOA has been associated with the progression of gastric cancer and been a druggable therapeutic target [144]. RHOA was downregulated by MIR156a incorporation with host miR-483, miR-125a-3p, miR-31-5p and miR-155-5p (Figure 6), and suppression of RHOA would reduce expression of IGF1R and INSR $[145,146]$. Therefore, galactose metabolic pathways including Warburg effect (aerobic glycolysis) would be inhibited, and simultaneously cell proliferation signals would be blocked through IGF1R. Further, host miR-31-5p upregulation reduced ROHA expression and blocked tumorigenicity $[147,148]$. It is suggested that fresh vegetable's effects of anticancer in the stomach would be enhanced by fresh vegetable MIR156a diet cooperated with host miRNAs, such as miR-31-5p. In the case of $H$. pylori infection with fresh vegetable, plant MIR156a incorporation and upregulation of miR-143-3p by $H$. pylori infection inhibited RHOA, HRAS and KRAS (Figure 6). Since HRAS and RHOA were implicated in transformation [149], and KRAS as well [150], 


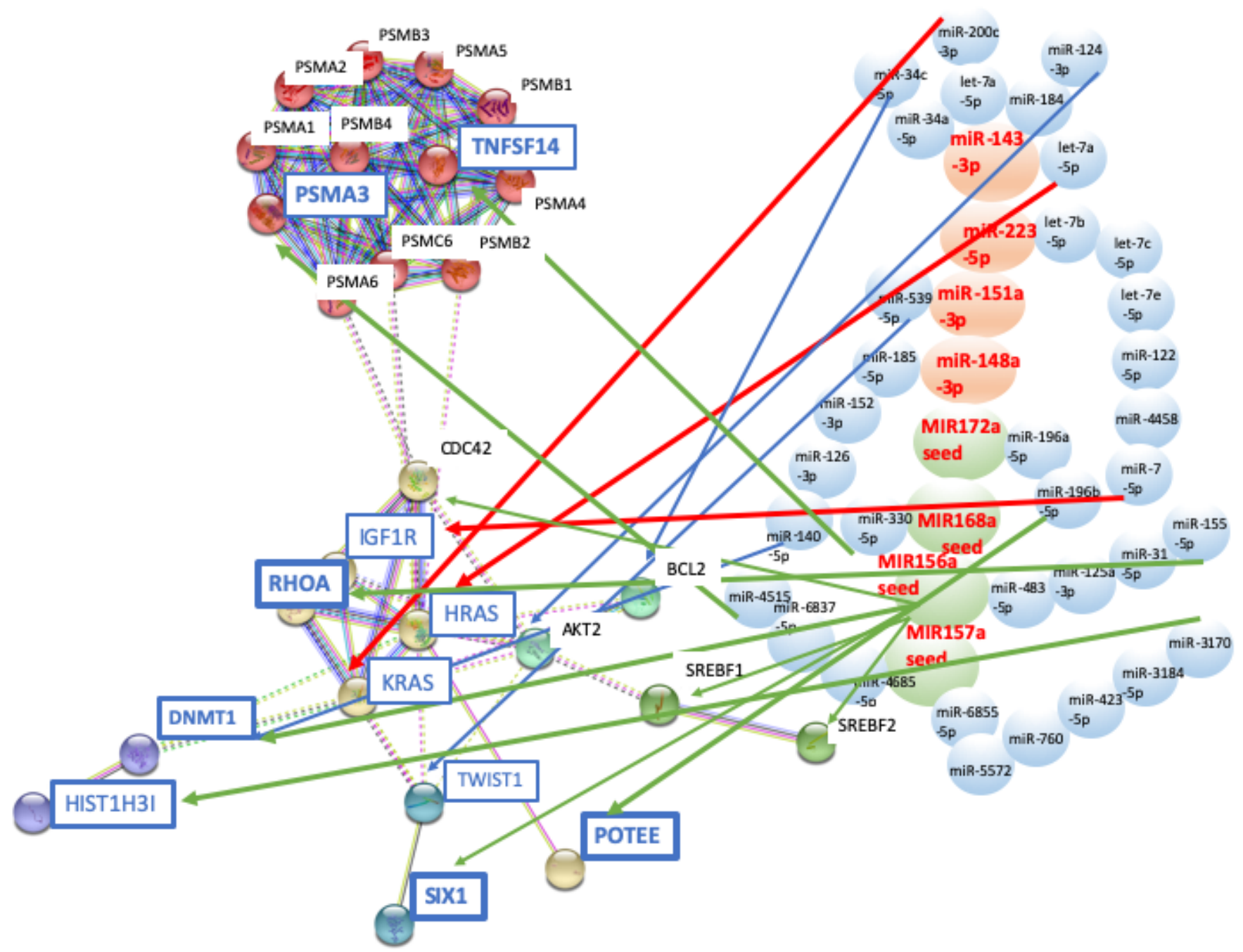

Figure 6. Coherence of the quantum code of vegetable miRNA and the miRNA hub in $H$. pylori infection. Four vegetable miRNAs' seed (green circles) and four miRNAs in $H$. pylori infection (orange circles) were applied for the METS analysis and the network was depicted. miRNAs: upregulation, red; downregulation, blue. Proteins: augmentation, red; suppression, blue.

fresh vegetable diet would augment suppression of carcinogenesis on the stomach under $H$. pylori infection. As described above, DNMT1 expression was high in gastric cancer [48], and Sine Oculis homeobox homologue (SIX) was also increased in gastric cancer. SIX was implicated in proliferation and invasion [151]. Consequently, three tumor-related proteins, ROHA, DNMT1 and SIX were downregulated by plant MIR156a feed (Figure 6).

Ankyrin domain family member E (POTEE) has been expressed in several cancers, such as the colon, prostate, lung, breast, ovary, lung and pancreas cancers $[152,153]$. POTEE was downregulated by plant MIR172a with host miR-196a-5p and miR-196b-5p (Figure 6). POTEF, which is an analogue of POTEE in the same group of POTE family, its antisense gene transcript repressed Toll-like receptor (TLR) and apoptosis as the antisense long non-coding RNA gene (POTEFAS1) [154] and POTEE expression was upregulated in macrophages exposed to conditioned medium of cancer cells grown under hypoxia [155]. These evidences showed that POTEE function would be at least implicated in inflammation through stresses such as hypoxia and bacterial infection. Therefore, reduction of POTEE expression may inhibit carcinogenesis via suppression of the stress. Thus, the data suggests that plant xenomiRNAs, such as vegetable (watermelon) MIR156a with host miRNAs may cure $H$. pylori-infected people from paradoxical pre-cancerous state.

Dietary $\beta$-carotene is provitamin A and when ate and absorbed, it is formed as retinol, one of the major forms of vitamin A. Watermelon contains phytochemicals, such as $\beta$-carotene and lycopene as the effector to miRNA expression [156,157]. Lycopene induced let-7f in prostate cancer cells and inhibited their proliferation in vitro [158]; however, administration of high doses of lycopene dietary supplement clinically resulted to be associated with a higher incidence of prostate cancer in phase I-II study [159]. All-trans retinoic acid (ATRA) is an isomer of retinoic acid and ATRA has been functioned as anticancer agents against different cancers including gastric cancer and been modulated expression of miRNAs in different types of cancer $[160,161]$. Although ATRA upregulated miR-302b expression in glioblastoma and ATRA inhibited cell proliferation of glioblastoma [162], alteration of miRNA profile by ATRA in gastric cancer has not yet been reported anywhere. Therefore, treatment with phytochemicals of watermelon was not leveraged in a cooperative relationship with host miRNAs integrated into the quantum network simulation. 
Fujii YR (2019) Quantum microRNA network analysis in gastric and esophageal cancers: Xenotropic plant microRNAs cure from cancerous paradox via Helicobacter pylori infection

\section{Statistical analysis of the relation between cancers and fresh vegetable diet}

To investigate whether $H$. pylori infection or fresh vegetable diet (watermelon) is pathogenetically associated with gastric cancer, statistical significance of the METS simulation has been examined. The valuation of statistical significance for carcinogenic pathology in the METS simulation was performed by the AUC in ROC using Excel and machine learning. As shown in Figure 7 and Table 3, tumorigenicity for gastric cancer in $H$. pylori infection (AUC: 0.57 in Excel, 0.4 in machine learning), and with fed fresh vegetables (AUC: 0.504 in Excel, 0.529 in machine learning) were statistically no significant compared with gastric cancer in the stage I (AUC: $0.78 \mathrm{p}<0.001$ in Excel, $0.9 \mathrm{p}<0.05$ in machine learning) and I-IV (AUC: $0.814 \mathrm{p}<0.001$ in Excel, 0.986 $\mathrm{p}<0.001$ in machine learning). The AUC of ESCC 0 -I and I-IV as the control were $0.676(\mathrm{p}<0.001)$ and $0.768(\mathrm{p}<0.001)$, respectively. By deep machine learning, the AUC of gastric and oesophageal cancers in the stage I-IV were $0.986(\mathrm{p}<0.001)$ and $0.924(\mathrm{p}<0.01)$, respectively. Accuracy and precision were 0.971 and 0.965 in stage I-IV gastric cancer. In stage I-IV ESCC, the accuracy and precision were 0.818 and 0.947 , respectively (Table 3 ), respectively. The statistical analysis from miRNA diagnostic marker data suggested in the quantum network that H.pylori infection (Figure 7, orange lines) and $H$. pylori infection with fresh vegetables and fruits (Figure 7 , gray lines) would not be related to carcinogenesis upon the human stomach.

\section{Conclusion}

Liquid biopsy is an important tool for clinical diagnosis to predict early signs of human diseases. The miRNA panel in the circulating
AUC curve of ESCC
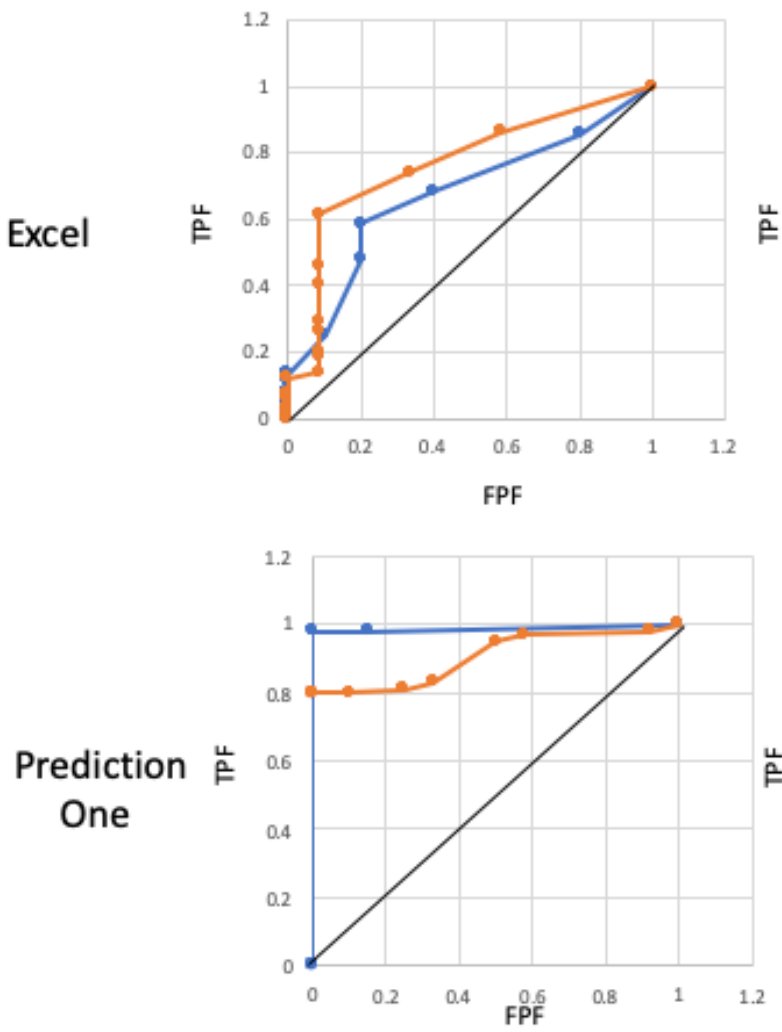

\section{AUC curve of GC}
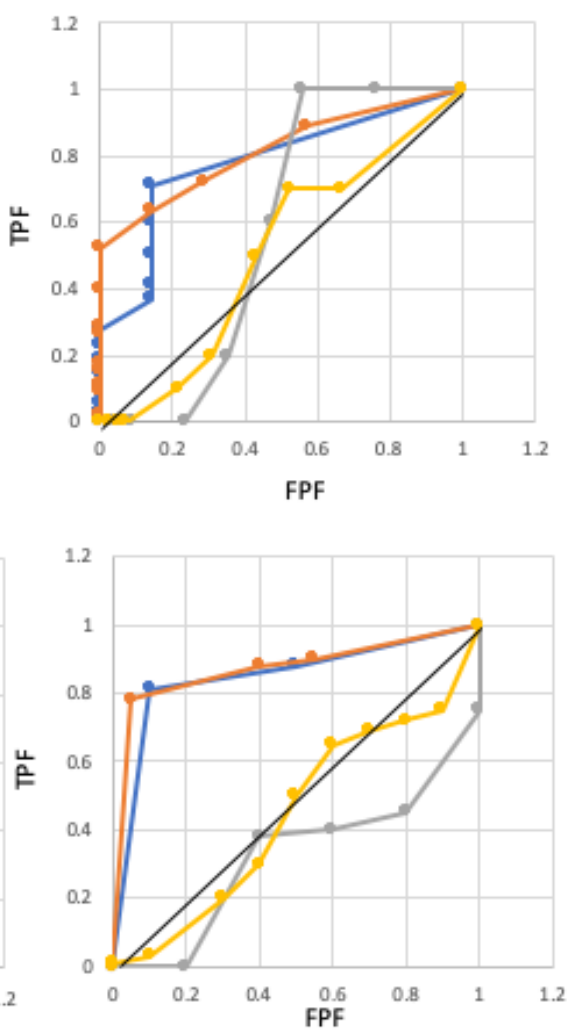

Figure 7. The AUC in ROC of ESCC, GC, H. pylori infection and vegetable diet. Statistical significance of the METS simulation has been analysed in ESCC (the left graphs) and GC (the right graphs) with the AUC by Excel (the upper graphs) and deep learning of Prediction One (the lower graphs). In ESCC, ROCs in blue and in brown showed as tumorigenicity of ESCC stage 0 -I and stage I-IV, respectively. In GC, ROCs in blue and brown were presented in GC stage I and stage I-IV, respectively. H. pylori infection upon GC carcinogenesis: orange, H. pylori + vegetable (watermelon) upon GC carcinogenesis: gray.

Table 3. Statistical analysis of miRNAs association with cancers

\begin{tabular}{|c|c|c|c|c|c|c|c|}
\hline \multirow[b]{2}{*}{$\begin{array}{c}\text { Cancer \& infection } \\
\& \text { Food }\end{array}$} & \multirow[b]{2}{*}{ Cancer stage } & \multicolumn{2}{|c|}{ Excel* } & \multicolumn{4}{|c|}{ Prediction One** } \\
\hline & & AUC & $\mathrm{p}$ value & AUC & Accuracy & Precision & $\mathrm{p}$ value \\
\hline \multirow[t]{2}{*}{ ESCC } & $0-\mathrm{I}$ & 0.676 & $\mathrm{p}<0.001$ & 0.999 & 0.992 & 1 & $\mathrm{p}<0.001$ \\
\hline & I-IV & 0.768 & $\mathrm{p}<0.001$ & 0.924 & 0.818 & 0.947 & $\mathrm{p}<0.01$ \\
\hline \multirow[t]{2}{*}{ GC } & I & 0.78 & $\mathrm{p}<0.001$ & 0.9 & 0.812 & 0.869 & $\mathrm{p}<0.05$ \\
\hline & I-IV & 0.814 & $\mathrm{p}<0.001$ & 0.986 & 0.971 & 0.965 & $\mathrm{p}<0.001$ \\
\hline Pylori & & 0.57 & $\mathrm{p}<0.05$ & 0.4 & 0.692 & 0.844 & $\mathrm{p}<0.05$ \\
\hline Pylori+Vegetable & & 0.504 & $\mathrm{p}<0.05$ & 0.529 & 0.827 & 0.824 & $\mathrm{p}<0.01$ \\
\hline
\end{tabular}


Fujii YR (2019) Quantum microRNA network analysis in gastric and esophageal cancers: Xenotropic plant microRNAs cure from cancerous paradox via Helicobacter pylori infection

system would be the first choice of a biomarker. An idea of the panel of miRNAs is unique one because multi-targeting character of miRNAs is deeply distinct from approximate one-to-one correspondence of $\mathrm{mRNA} /$ protein interaction. The network analysis of miRNA/mRNA requires to architect a high dimensional space for understanding of the etiological significance in the miRNA biomarker panel, therefore, algorithm of METS analysis based on quantum calculation has been newly developed from a computation processing with high dimensions of miRNA/miRNA and miRNA/mRNA interactions.

It has been shown by the quantum network analysis that the biological and pharmaceutical characters of the miRNA panel could be etiologically elucidated in human cancers $[24,25]$. It means that the miRNA panels would be available for a biomarker of human diseases' diagnosis and prediction. Although $H$. pylori infection may be on the minus one stage of gastric cancer, in argument, at the minus one stage of cancer, it would be difficult for such tiny lesion part of cancer to be specified. But by the METS analysis, it was shown that $H$. pylori infection may additionally contribute to progression of malignancy in gastric cancer cells via glucose metabolic pathway on a paradox in Zen Buddhism riddle. Further, plant xenomiRNAs in fresh vegetables and fruits could cure $H$. pylori-infected people from the paradoxical precancerous state at least in silico, which would suggest that the minus one stage of cancer can be reversible to healthy state. In turn, the environmental stress, such as mal-diets, long-term less fresh vegetable and fruit, would dysregulate miRNA expression, additionally it may contribute most for increasing risk of gastric cancer. Therefore, after the life-style habits were changed or miRNA therapeutic agents were supplied to the minus one stage people, it may be enough to examine miRNA reversion to healthy profile because $H$. pylori infection would be reversibly oncogenic by eradication.

The quantum miRNA language would be useful for stage minus one diagnosis with miRNAs not only to develop miRNA and sponge medicines but also to make medical care guideline and to health guidance support system. Further investigations need for clinical usage.

\section{References}

1. Rawla P, Barsouk A (2019) Epidemiology of gastric cancer: global trends, risk factors and prevention. Gastroenterol Rev 14: 26-38. [Crossref]

2. Sadat Yousefi M, Sharifi-Esfahani M, Pourgholam-Amiji N, Afshar M, SadeghiGandomani H, et al. (2018) Esophageal cancer in the world: incidence, mortality and risk factors. Biomed Res Ther 5: 2504-2517.

3. Ahmed N (2005) 23 years of the discovery of Helicobacter pylori: Is the debate over? Ann Clin Microbiol Antimicrob 4: 17. [Crossref]

4. Mahachai V, Vilaichone RK, Pittayanon R, Rojbrowonwitaya J, Leelakusolvong S, et al. (2018) Helicobacter pylori management in ASIAN: the Bangkok consensus report. J Gastroenterol Hepatol 33: 37-56. [Crossref]

5. Poyrazoglu OB, Dulger AC, Gultepe BS (2017) Helicobacter pylori infection in patients with esophageal squamous cell cancer. Clinics 72: 150-153. [Crossref]

6. Mukaisho K, Nakayama T, Hagiwara T, Hattori T, Sugihara H (2015) Two distinct etiologies of gastric cardia adenocarcinoma: interactions among $\mathrm{pH}$, Helicobacter pylori, and bile acids. Front Microbiol 6: 412. [Crossref]

7. Yoshikawa M, Osone T, Fujii YR (2016) MicroRNA memory I: the positive correlation between synergistic effects of microRNAs in cancer and a novel quantum scoring system. J Adv Med Phar Sci 5: 1-16.

8. Osone T, Yoshikawa M, Fujii YR (2016) MicroRNA memory II: a novel scoring integration model for prediction of human disease by microRNA/microRNA quantum multi-interaction. J Adv Med Phar Sci 5: 1-18.

9. Fujii YR (2017) The microRNA 2000: from HIV-1 to healthcare. Scientific Research Publishing, Inc., Irvine, CA.
10. Li BS, Zhao YL, Guo G, Li W, Zhu ED, et al. (2012) Plasma microRNAs, miR-223, miR-21 and miR-218, as novel potential biomarkers for gastric cancer detection. PLoS One 7: e41629. [Crossref]

11. Zhu C, Ren C, Han J, Ding Y, Du J, et al. (2014) A five-microRNA panel in plasma was identified as potential biomarker for early detection of gastric cancer. Brit J Cancer 110: 2291-2299. [Crossref]

12. Tsujiura M, Ichikawa D, Komatsu S, Shiozaki A, Takeshita H, et al. (2010) Circulating microRNAs in plasma of patients with gastric cancers. Br J Cancer 102: 1174-1179. [Crossref]

13. Liu HN, Wu H, Tseng YJ, Chen YJ, Zhang DY, et al. (2018) Serum microRNA signatures and metabolomics have high diagnostic value in gastric cancer. BMC Cancer 18: 415. [Crossref]

14. Zhang L, Dong B, Ren P, Ye H, Shi J, et al. (2018) Circulating plasma microRNAs in the detection of esophageal squamous cell carcinoma. Onc Let 16: 3303-3318. [Crossref]

15. Zhou X, Wen W, Zhu J, Huang Z, Zhang L, et al. (2017) A six-microRNA signature in plasma was identified as a potential biomarker in diagnosis of esophageal squamous cell carcinoma. Oncotarget 8: 34468-34480. [Crossref]

16. Zheng D, Ding Y, Ma Q, Zhao L, Guo X, et al. (2019) Identification of serum microRNAs as novel biomarkers in esophageal squamous cell carcinoma using feature selection algorithms. Front Onc 8: 674. [Crossref]

17. Wang K, Chen D, Meng Y, Xu J, Zhang Q (2018) Clinical evaluation of 4 types of microRNA in serum as biomarkers of esophageal squamous cell carcinoma. Onc Let 16: 1196-1204. [Crossref]

18. Hui B, Chen X, Hui L, Xi R, Zhang X (2015) Serum miRNA expression in patients with esophageal squamous cell carcinoma. Onc Let 10: 3008-3012. [Crossref]

19. Xu H, Yao Y, Meng F, Qian X, Jiang X, et al. (2015) Predicitve value of serum miR$10 \mathrm{~b}, \mathrm{miR}-29 \mathrm{c}$, and miR-205 as promising biomarkers in esophageal squamous cel carcinoma screening. Medicine 94: 1-5. [Crossref]

20. Yu J, Xu Q, Zhang X, Zhu M (2018) Circulating microRNA signatures serve as potential diagnosis biomarkers for Helicobacter pylori infection. $J$ Cell Biochem 30324743. [Crossref]

21. Fujii YR (2018) Quantum language of microRNA: application for new cancer therapeutic targets. Methods Mol Biol 1733: 145-157. [Crossref]

22. Fujii YR (2013) The RNA gene information: retroelement-microRNA entangling as the RNA quantum code. Methods Mol Biol 936: 47-67. [Crossref]

23. Yoshikawa M, Fujii YR (2016) Human ribosomal RNA-derived resident microRNAs as the transmitter of information upon the cytoplasmic cancer stress. Biomed Res Int 2016: 7562085. [Crossref]

24. Fujii YR (2019) Cancer simulation from stage minus one by quantum microRNA language: lung, colorectal and pancreatic cancers. Med One 4: e190023.

25. Fujii YR (2018) The quantum language of the microRNA gene and anti-cancer: with a dynamic computer simulation of human breast cancer drug resistance. Integr $\mathrm{Mol}$ Med 5: 1-13.

26. Correa P, Piazuelo MB (2011) Helicobacter pylori infection and gastric adenocarcinoma US Gastroenterol. Hepatol Rev 7: 59-64. [Crossref]

27. Parsonnet J, Friedman GD, Orentreich N, Vogelman H (1997) Risk for gastric cancer in people with CagA positive or CagA negative Helicobacter pylori infection. Gut 40: 297-301. [Crossref]

28. Foegeding NJ, Raghunathan K, Campbell AM, Kim SW, Lau KS, et al. (2019) Intracellular degradation Helicobacter pylori VacA toxin as a determinant of gastric epithelial cell viability. Infect Immun 87: e00783-18. [Crossref]

29. Yang F, Xu Y, Liu C, Ma C, Zou S, et al. (2018) NF-kB/miR-223-3p/ARID1A axis is involved in Helicobacter pylori CagA-induced gastric carcinogenesis and progression. Cell Death Disease 9: 12. [Crossref]

30. Ma L, Chen Y, Zhang B, Liu G (2014) Increased microRNA-223 in Helicobacte pylori-associated gastric cancer contributed to cancer cell proliferation and migration. Biosci Biotech Biochem 78: 602-608. [Crossref]

31. Li S, Li Z, Guo F, Qin X, Liu B, et al. (2011) miR-223 regulates migration and invasion by targeting artemin in human esophageal carcinoma. J Biomed Sci 18: 24. [Crossref]

32. Masciarelli S, Fontemaggi G, Di Agostino S, Donzelli S, Carcarino E, et al. (2014) Gain-of-function mutant p53 downregulates miR-223 contributing to chemoresistance of cultured tumor cells. Oncogene 33: 1601-1608. [Crossref] 
Fujii YR (2019) Quantum microRNA network analysis in gastric and esophageal cancers: Xenotropic plant microRNAs cure from cancerous paradox via Helicobacter pylori infection

33. Dou L, Han K, Xiao M, Lv F (2019) miR-223-5p Suppresses Tumor Growth and Metastasis in Non-Small Cell Lung Cancer by Targeting E2F8. Oncol Res 27: 261268. [Crossref]

34. Shoitani A, Uedo N, Iishi H, Murao T, Kanzaki T, et al. (2012) H. pylori eradication did not improve dysregulation of specific oncogenic miRNAs in intestinal metaplastic glands. J Gastroenterol 47: 988-998. [Crossref]

35. Wang J, Wu J, Cheng Y, Jiang Y, li G (2016) Over-expression of microRNA-223 inhibited the proinflammatory responses in Helicobacter pylori-infection macrophages by down-regulation IRAK-1. Am J Transl Res 8: 615-622. [Crossref]

36. Matsushima K, Isomoto H, Inoue N, Nakayama T, Hayashi T, et al. (2011) MicroRNA signatures in Helicobacter pylori-infected gastric mucosa. Int J Cancer 128: 361-370. [Crossref]

37. Callery MP (2006) Helicobacter pylori in gastric cancer: Friend or foe? Gastroenterology 131: 966-967. [Crossref]

38. Sasaki T, Yamashita Y, Kuniyasu H (2015) AKT plays a crucial role in gastric cancer. Oncol Lett 10: 607-611. [Crossref]

39. Wang F, Liu J, Zou Y, Jiao Y, Huang Y, et al. (2017) MicroRNA-143-3p, up-regulation in H. pylori-positive gastric cancer, suppresses tumor growth, migration and invasion by directly targeting AKT2. Oncotarget 8: 28711-28724. [Crossref]

40. Xu W, Huang Y, Yang Z, Hu Y, Shu X, et al. (2018) Helicobacter pylori promotes gastric epihtlial cell survival through the PLKI/PI3K/Akt pathway. Oncotargets Ther 11: 5703-5713. [Crossref]

41. Xie Y, Liu L (2018) Analysis of correlation between HP infection and activation of $\mathrm{PI} 3 \mathrm{~K} / \mathrm{Akt}$ pathway in mucosal tissues of gastric cancer and precancerous lesion. Oncol Lett 16: 5615-5620. [Crossref]

42. Mundi PS, Sachdev J, McCourt C, Kalinsky K, et al. (2016) AKT in cancer: new molecular insights and advances in drug development. Br J Clin Pharmacol 82: 943956. [Crossref]

43. Gonzalez E, McGraw TE (2009) The Akt kinases: isoform specificity in metabolism and cancer. Cell Cycle 8: 2502-2508. [Crossref]

44. Sahlberg SH, Mortensen AC, Haglöf J, Engskog MK, Arvidsson T, et al. (2017) Different functions of AKT1 and AKT2 in molecular pathways, cell migration and metabolism in colon cancer. Int J Oncol 50: 5-14. [Crossref]

45. Duan L, Maki CG (2016) The IGF-1R/AKT pathway determines cell fate in response to p53. Transl Cancer Res 5: 664-675. [Crossref]

46. Yuan J, Yin Z, Tao K, Wang G1, Gao J (2018) Function of insulin-like growth factor 1 receptor in cancer resistance to chemotherapy. Oncol Lett 15: 41-47. [Crossref]

47. Qian J, Luo Y, Gu X, Zhan W, Wang X (2013) Twist 1 promotes gastric cancer cell proliferation through up-regulation of FoxM1. PLoS One 8: e77625. [Crossref]

48. Ma T, Li H, Sun M, Yuan Y, Sun LP (2017) DNMT1 overexpression predicting gastric carcinogenesis, subsequent progression and prognosis: a meta and bioinformatic analysis. Oncotarget 8: 96396-96408. [Crossref]

49. Shi H, Chen X, Jiang H, Wang X, Yu H, et al. (2018) miR-148a suppresses cell invasion and migration in gastric cancer by targeting DNA methyltransferase 1. Oncol Lett 15: 4944-4950. [Crossref]

50. Zhu A, Xia J, Zuo J, Jin S, Zhou H, et al. (2012) MicroRNA-148a is silenced by hypermethylation and interacts with DNA methyltransferase 1 in gastric cancer. Med Oncol 29: 2701-2709. [Crossref]

51. Yang ZM, Chen WW, Wang YF (2012) Gene expression profiling in gastric mucosa from Helicobacter pylori-infected and uninfected patients undergoing chronic superficial gastritis. PLoS One 7: e33030. [Crossref]

52. Pareja F, Brandes AH, Basili T, Selenica P, Geyer FC, et al. (2018) Loss-of-function mutations in ATP6AP1 and ATP6AP2 in granular cell tumors. Nat Commun 9: 3533. [Crossref]

53. Trepiccione F, Gerber SD, Grahammer F, López-Cayuqueo KI, Baudrie V, et al. (2016) Renal Atp6ap2/(pro)renin receptor is required for normal vacuolar H+-ATPase function but not for the renin-angiotensin system. J Am Soc Nephrol 27: 3320-3330. [Crossref]

54. Peng YC, Huang LR4, Ho HC5, et al. (2017) The effect of proton pump inhibitors on the gastric mucosal microenvironment. Adv Clin Exp Med 26: 39-43. [Crossref]

55. Cheung KS, Chan EW, Wong AY, Chen L, Wong IC, et al. (2018) Long-term proton pump inhibitors and risk of gastric cancer development after treatment for Helicobacter pylori: a population-based study. Gut 67: 28-35. [Crossref]
56. Liu P, Chen H, Han L, Zou X, Shen W (2015) Expression and role of V1A subunit of V-ATPases in gastric cancer cells. Int J Clin Oncol 20: 725-735. [Crossref]

57. Whitton B, Okamoto H, Packham G, Crabb SJ (2018) Vacuolar ATPase as a potential therapeutic target and mediator of treatment resistance in cancer. Cancer Med 7: 38003811. [Crossref]

58. Joo MK, Park JJ, Chun HJ (2019) Proton pump inhibitor: The dual role in gastric cancer. World J Gastroenterol 25: 2058-2070. [Crossref]

59. Zhang BG, Hu L, Zang MD, Wang HX, Zhao W, et al. (2016) Helicobacter pylori CagA induces tumor suppressor gene hypermethylation by upregulating DNMT1 via AKTNFKB pathway in gastric cancer development. Oncotarget 7: 9788-9800. [Crossref]

60. Wen Y, Feng J, Sachs G (2013) Helicobacter pylori 5' ureB-sRNA, a cis-encoded antisense small RNA, negatively regulates ure $\mathrm{AB}$ expression by transcription termination. J Bacteriol 195: 444-452. [Crossref]

61. Chu A, Liu J, Yuan Y, Gong Y (2019) Comprehensive analysis of aberrantly expressed ceRNA network in gastric cancer with and without H. pylori infection. $J$ Cancer 10: 853-863. [Crossref]

62. Yuan C, Zhang Y, Tu W, Guo Y (2019) Integrated miRNA profiling and bioinformatics analysis reveal upregulated miRNAs in gastric cancer. Oncol Lett 18: 1979-1988. [Crossref]

63. Akopyanz N, Bukanov NO, Westblom TU, Berg DE (1992) PCR-based RFLP analysis of DNA sequenc diversity in the gastric pathogen Helicobacter pylori. Nucleic Acids Res 20: 6221-6225. [Crossref]

64. Suerbaum S, Michetti P (2002) Helicobacter pylori infection. N Engl J Med 347: 1175 1186. [Crossref]

65. Terasawa T, Hamashima C, Kato K, Miyashiro I, Yoshikawa T, et al. (2019) Helicobacter pylori eradication treatment for gastric carcinoma prevention in asymptomatic or dyspeptic adults: systematic review and Bayesian meta-analysis of randomised controlled trials. BMJ Open 9: e026002. [Crossref]

66. Doorakkers E, Lagergren J, Engstrand L, Brusselaers N (2016) Eradication of Helicobacter pylori and Gastric Cancer: A Systematic Review and Meta-analysis of Cohort Studies. J Natl Cancer Inst 108. [Crossref]

67. Rokkas T, Rokka A, Portincasa P (2017) A systematic review and meta-analysis of the role of Helicobacter pylori eradication in preventing gastric cancer. Ann Gastroenterol 30: 1-10. [Crossref]

68. Seta T, Takahashi Y, Noguchi Y, Shikata S, Sakai T, et al. (2017) Effectiveness of Helicobacter pylori eradication in the prevention of primary gastric cancer in healthy asymptomatic people: a systematic review and meta-analysis comparing risk ratio with risk difference. PLoS One 12: $\mathrm{e} 0183321$. [Crossref]

69. Callery MP (2006) Helicobacter pylori in gastric cancer: Friend or foe? Gastroenterology 131: 966-967. [Crossref]

70. Anderson LA, Tavilla A, Brenner H, Luttmann S, Navarro C, et al. (2015) Surviva for esophageal, stomach and small intestine cancers in Europe 1999-2007: results from EUROCARE-5. Eur J Cancer 51: 2144-2157. [Crossref]

71. Schmidt N, Peitz U, Lippert H, Malfertheiner P (2005) Missing gastric cancer in dyspepsia. Aliment Pharmacol Ther 21: 813-820. [Crossref]

72. Pectasides D, Mylonakis A, Kostopoulou M, Papadopoulou M, Triantafillis D, et al. (1997) CEA, CA 19-9, and CA-50 in monitoring gastric carcinoma. Am J Clin Oncol 20: 348-353. [Crossref]

73. Oishi Y, Watanabe Y, Yoshida Y, Sato Y, Hiraishi T, et al. (2012) Hypermethylation of Sox17 gene is useful as a molecular diagnosis application in early gastric cancer. Tumour Biol 33: 383-393. [Crossref]

74. Compare D, Rocco A, Liguori E, D'Armlento FP, Persico G, et al. (2011) Global DNA hypomethylation is an early event in Helicobacter pylori-related gastric carcinogenesis. J Clin Pathol 64: 677-682. [Crossref]

75. Yi HK, Kim SY, Hwang PH, Kim CY, Yang DH, et al. (2005) Impact of PTEN on the expression of insulin-like growth factors (IGFs) and IGF-binding proteins in human gastric adenocarcinoma cells. Biochem Biophys Res Comm 330: 760-767. [Crossref]

76. Xu WT, Yang Z, Lu NH (2014) Role of PTEN (phosphatase and tensin homolog) in gastric cancer development and progression. Asian Pac J Cancer Prev 15: 17-24 [Crossref]

77. Xu W, Yang Z, Xie C, Zhu Y, Shu X, et al. (2018) PTEN lipid phosphatase inactivation links the hippo and PI3K/Akt pathways to induce gastric cancer. J Exp Clin Cancer Res 37: 198. [Crossref] 
Fujii YR (2019) Quantum microRNA network analysis in gastric and esophageal cancers: Xenotropic plant microRNAs cure from cancerous paradox via Helicobacter pylori infection

78. Li L, Song Y, Liu Q, Liu X, Wang R, et al. (2018) Low expression of PTEN is essential for maintenance of a malignant state in human gastric adenocarcinoma via upregulation of p-AURKA mediated by activation of AURKA. Int J Mol Med 41: 3629-3641. [Crossref]

79. Zheng HC, Li YL, Sun JM, Yan XF, Li XH, et al. (2003) Growth, invasion, metastasis, differentiation, angiogenesis and apoptosis of gastric cancer regulated by expression of PTEN encoding products. World Gastroenterol 9: 1662-1666. [Crossref]

80. Emami SS, Nekouian R, Akbari A, Faraji A, Abbasi V, et al. (2019) Evaluation of circulating miR-21 and miR-222 as diagnostic biomarkers for gastric cancer. J Cancer Res Ther 15: 115-119. [Crossref]

81. Zhang L, Huang Z, Zhang H, Zhu M, Zhu W, et al. (2017) Prognostic value of candidate microRNAs in gastric cancer: a validation study. Cancer Biomark 18: 221230. [Crossref]

82. Hou X, Zhang M, Qiao H (2015) Diagnostic significance of miR-106a in gastric cancer. Int J Clin Exp Pathol 8: 13096-13101. [Crossref]

83. Li F, Guo Y, Liu J, Zhang R (2017) The significance of elevated plasma expression of microRNA 106b 25 clusters in gastric cancer. PLoS One 12: e 0178427. [Crossref]

84. Hewitt LC, Saito Y, Wang T, Matsuda Y, Oosting J, et al. (2019) KRAS status is related to histological phenotype in gastric cancer: results from a large multicenter study. Gastric Cancer 2019: 1-16. [Crossref]

85. Watarai J, Tanaka A, Tanabe H, Sato R, Moriichi K, et al. (2006) K-ras mutation and kinetics in Helicobacter pylori associated gastric intestinal metaplasia: a comparison before and after eradication in patients with chronic gastritis and gastric cancer. $J$ Clin Pathol 60: 921-926. [Crossref]

86. Jabini R, Eghbali SA, Ayatollahi H, Sheikhi M, Farzanehfar M (2019) Analysis of KRAS gene mutation associated with Helicobacter pylori infection in patients with gastric cancer. Iran J Basic Med 22: 529-533.

87. Hunt JD, Mera R, Strimas A, Gillespie AT, Ruiz B, et al. (2001) KRAS mutations are not predictive for progression of preneoplastic gastric cancer. Cancer Epidemiol Biomarker Prev 10: 79-80. [Crossref]

88. Song IS, Oh NS, Kim HT, Ha GH, Jeong SY, et al. (2009) Human ZNF312b promotes the progression of gastric cancer by transcriptional activation of the K-ras gene. Cancer Res 69: 3131-3139. [Crossref]

89. Tang R, Yang C, Ma X, Wang Y, Luo D, et al. (2016) MiR-let-7a inhibits cell proliferation, migration, and invasion by down-regulating PKM2 in gastric cancer. Oncotarget 7: 5973-5984. [Crossref]

90. Deng HX, Yu YY, Zhou AQ, Zhu JL, Luo LN, et al. (2017) Yangzheng Sanjie decoction regulates proliferation and apoptosis of gastric cancer cells by enhancing let-7a expression. World J Gasroenterol 23: 5538-5548. [Crossref]

91. Zhu J, Wang H, Xu S, Hao Y (2017) Clinicopathological and prognostic significance of HMGA2 overexpression in gastric cancer: a meta-analysis. Oncotarget 8: 100478100489. [Crossref]

92. Huang B, Yang J, Cheng Q, Xu P, Wang J, et al. (2018) Prognostic value of HMGA2 in human cancers: a meta-analysis based on literatures and TCGA database. Front Physiol 9: 776. [Crossref]

93. Voon DC, Wang H, Koo JK, Chai JH, Hor YT, et al. (2013) EMT-induced stemness and tumorigenicity are fueled by the EGFR/Ras pathway. PLoS One 8: e70427. [Crossref]

94. Voon DC, Wang H, Koo JK, Nguyen TA, Hor YT, et al. (2012) Runx3 protects gastric epithelial cells against epithelial-mesenchymal transition-induced cellular plasticity and tumorigenicity. Stem Cells 30: 2088-2099. [Crossref]

95. Gao Y, Xu D, Yu G, Liang J (2015) Overexpression of metabolic markers HK1 and PKM2 contributes to lymphatic metastasis and adverse prognosis in Chinese gastric cancer. Int. J Clin Exp Pathol 8: 9264-9271. [Crossref]

96. Zhang TB, Zhao Y, Tong ZX, Guan YF (2015) Inhibition of glucose-transporter 1 (GLUT-1) expression reversed Warburg effect in gastric cancer cell MKN45. Int J Clin Exp Med 8: 2423-2428. [Crossref]

97. Shefi-Friedman L, Wertheimer E, Shen S, Bak A, Accili D, et al. (2001) Increased IGFR activity and glucose transport in cultured skeletal muscle from insulin receptor null mice. Am J Physiol Endocrinol 281: E16-E24. [Crossref]

98. Li G, Barrett EJ, Ko SH, Cago W, Liu Z (2009) Insulin and insulin-like growth factor-I receptors differentially mediate insulin-stimulated adhesion molecule production by endothelial cells. Endocrinology 150: 3475-3482. [Crossref]

99. Heckl SM, Wiesener V, Behrens HM, Ulase D, Krüger S, et al. (2019) The expression of the insulin receptor in gastric cancer correlates with the HER2 status and may have putative therapeutic implication. Gastric Cancer 22: 1130-1142. [Crossref]
100. Valenzuela-Valderrama M, Cerda-Opazo P, Backert S, Gonzáles MF, Carrasco-Véliz $\mathrm{N}$, et al. (2019) The Helicobacter pylori urease virulence factor is required for the induction of hypoxia-induced factor-1 $\alpha$ in gastric cells. Cancers 11: E799. [Crossref]

101. Liu L, Zhao X, Zou H, Bai R, Yang K, et al. (2016) Hypoxia promotes gastric cancer malignancy partly through the HIF-1 $\alpha$ dependent transcriptional activation of the long non-coding RNA GAPLINC. Front Phys 7: 420. [Crossref]

102. Rupaimoole R, Wu SY, Pradeep S, Ivan C, Pecot CV, et al. (2014) Hypoxia-mediated downregulation of miRNA biogenesis promotes tumor progression. Nat Comm 5: 5202. [Crossref]

103. Joshi S, Wei J, Bishopric NH (2016) A cardiac myocyte-restricted Lin28/let-7 regulatory axis promotes hypoxia-mediated apoptosis by inducing the AKT signaling suppressor PIK3IP1. Biochem Biophys Acta 1862: 240-251. [Crossref]

104. Al Tameemi W, Dale TP, Al-Jumaily RMK, Forsyth NR (2019) Hypoxia-Modified Cancer Cell Metabolism. Front Cell Dev Biol 7: 4. [Crossref]

105. Eales KL, Hollinshead K, Tennant DA (2016) Hypoxia and metabolic adaptation of cancer cells. Oncogenesis 5: e190. [Crossref]

106. Xie FX, Zhang YP, Zheng QQ, Jin HC, Wang FL, et al. (2013) Helicobacter pylori infection and esophageal cancer risk: an updated meta-analysis. World $J$ Gastroenterol 19: 6098-6107. [Crossref]

107. Nie S, Chen T, Yang X, Huai P, Lu M (2014) Association of Helicobacter pylori infection with esophageal adenocarcinoma and squamous cell carcinoma: a metaanalysis. Dis Esophagus 27: 645-653. [Crossref]

108. Zhuo X, Zhang Y, Wang Y, Zhuo W, Zhu Y, et al. (2008) Helicobacter pylori infection and oesophageal cancer risk: association studies via evidence-based metaanalysis. Clin Oncol 20: 757-762. [Crossref]

109. Bray F, Ferlay J, Soerjomataram I, Siegel RL, Torre LA, et al. (2018) Global cancer statistics 2018: GLOBOCAN estimates of incidence and mortality worldwide for 36 cancers in 185 countries. CA. Cancer J Clin 68: 394-424. [Crossref]

110. Mealy K, Feely J, Reid I, McSweeney J, Walsh T, et al. (1996) Tumour marker detection in oesophageal carcinoma. Eur J Surg Oncol 22: 505-507. [Crossref]

111. Pennathur A, Gibson MK, Jobe BA, Luketich JD (2013) Oesophageal carcinoma Lancet 381: 400-412.

112. Wang GQ, Jiao GG, Chang FB, Fang WH, Song JX, et al. (2004) Long-term results of operation for 420 patients with early squamous cell esophageal carcinoma discovered by screening. Ann Thorac Surg 77: 1740-1744. [Crossref]

113. Al Rashid ST, Dellaire G, Cuddihy A, Jalali F, Vaid M, et al. (2005) Evidence for the direct binding of phosphorylated $\mathrm{p} 53$ to sites of DNA breaks in vivo. Cancer Res 65 : 10810-10821. [Crossref]

114. Bartek J, Lukas J (2003) Chk1 and Chk2 kinases in checkpoint control and cancer. Cancer Cell 3: 421-429. [Crossref]

115. Sarkaria JN, Busby EC, Tibbetts RS, Roos P, Taya Y, et al. (1999) Inhibition of ATM and ATR kinase activities by the radiosensitizing agent, caffeine. Cancer Res 59: 4375-4382. [Crossref]

116. Choi M, Kipps T, Kurzrock R (2016) ATM mutations in cancer: therapeutic implications. Mol Cancer Ther 15: 1781-1791. [Crossref]

117. Deng W, Tsao SW, Mak GW, Tsang CM, Ching YP, et al. (2011) Impact of G2 checkpoint defect on centromeric instability. Oncogene 30: 1281-1289.

118. Ma YC, Su N, Shi XJ, Zhao W, Ke Y, et al. (2015) Jaridonin-induced G2/M phase arrest in human esophageal cancer cells is caused by reactive oxygen speciesdependent Cdc2-tyr15 phosphorylation via ATM-Chk1/2-Cdc25C pathway. Toxicol Appl Pharmacol 282: 227-236. [Crossref]

119. Concepcion CP, Bonetti C, Ventura A (2012) The microRNA-17-92 family of microRNA clusters in development and disease. Cancer J 18: 262-267. [Crossref]

120. Khuu C, Sehic A, Eide L, Osmundsen H (2016) Anti-proliferative properties of miR-20b and miR-363 from the miR-106a-363 cluster on human carcinoma cells. Microrna 5: 19-35. [Crossref]

121. Kreis NN, Louwen F, Yuan J (2019) The multifaced p21 (Cip1/Waf1/CDKN1A) in cell differentiation, migration and cancer therapy. Cancers 11: 1220. [Crossref]

122. Worku D, Jouhra F, Jiang G W, Patani N, Newbold RF, et al. (2008) Evidence of a tumor suppressive function of E2F1 gene in human breast cancer. Anticancer Res 28 2135-2140. [Crossref] 
Fujii YR (2019) Quantum microRNA network analysis in gastric and esophageal cancers: Xenotropic plant microRNAs cure from cancerous paradox via Helicobacter pylori infection

123. Sun Z, Bi M, Zhang Z, Liu X, Wang Z (2015) Negative expression of PTEN identifies high risk for lymphatic-related metastasis in human esophageal squamous cell carcinoma. Oncol Let 33: 3024-3032. [Crossref]

124. Koukourakis MI, Giatromanolaki A, Skarlators J, Corti L, Blandamura S, et al. (2001) Hypoxia inducible factor (HIF-1a and HIF-2a) expression in early esophageal cancer and response to photodynamic therapy and radiotherapy. Cancer Res 61: 1830-1832.

125. Cicchini C, de Nonno V, Battistelli C, Cozzolino AM, De Santis Puzzonia M, et al. (2015) Epigenetic control of EMT/MET dynamics: HNF4 impacts DNMT3s through miRs-29. Biochem Biophys Acta 1849: 919-929. [Crossref]

126. Witte T, Plass C, Gerhauser C (2014) Pan-cancer patterns of DNA methylation. Genome Med 6: 66. [Crossref]

127. Lu T, Chen D, Wang Y, Sun X, Li S, et al. (2019) Identification of DNA methylationdriven genes in esophageal squamous cell carcinoma: a study based on The Cancer Genome Atlas. Cancer Cell Inter 19: 52. [Crossref]

128. Roy R, Kandimalla R, Sonohara F, Koike M, Kodera Y, et al. (2018) A comprehensive methylation signature identifies lymphonode metastasis in esophageal squamous cell carcinoma. Inter J Cancer 144: 1160-1169. [Crossref]

129. Zhang Y, Xu L, Li A, Han X (2019) The role of ZEB1 in tumorigenic progression and epigenetic modification. Biomed Pharmacother 110: 400-408. [Crossref]

130. Ishibashi O, Akagi I, Ogawa Y, Inui T (2018) MiR-141-3p is upregulated in esophageal squamous cell carcinoma and targets pleckstrin homology domain leucine-rich repeat protein phsoshpatase-2, a negative regulator of the PI3K/AKT pathway. Biochem Biophys Res Commun 501: 507-513. [Crossref]

131. Zhao BS, Liu SG, Wang TY, Ji YH, Qi B, et al. (2013) Screening of microRNA in patients with esophageal cancer at same tumor node metastasis stage with different prognosis. Asian Pacific J Cancer Prev 14: 139-143. [Crossref]

132. Cui XB, Peng H, Li RR, Mu JQ, Yang L, et al. (2017) MicroRNA-34a functions as a tumor suppressor by directly targeting oncogenic PLCE1 in Kazakh esophageal squamous cell carcinoma. Oncotarget 8: 92454-92469. [Crossref]

133. Yang L, Song X, Zhu J, Li M, Ji Y, et al. (2017) Tumor suppressor microRNA$34 \mathrm{a}$ inhibits cell migration and invasion by targeting MMP-2/MMP-9/FNDC3B in esophageal squamous cell carcinoma. Int J Onc 51: 378-388. [Crossref]

134. Cui X, Zhao Z, Liu D, Guo T, Li S, et al. (2014) Inactivation of miR-34a by aberrant CpG methylation in Kazakh patients with esophageal carcinoma. J Exp Clin Cancer Res 33: 20. [Crossref]

135. Chen X, Hu H, Guan X, Xiong G, Wang Y, et al. (2012) CpG island methylation status of miRNAs in esophageal squamous cell carcinoma. Int J Cancer 130: 16071613. [Crossref]

136. Zhao Q, Mao Q, Zhao Z, Dou T, Wang Z, et al. (2018) Prediction of plant-derived xenomiRs from plant miRNA sequences using random forest and one-dimensional convolutional neural network models. BMC Genomics 19: 839. [Crossref]

137. Minutolo A, Potestà M, Gismondi A, Pirrò S, Cirilli M, et al. (2018) Olea europaea small RNA with functional homology to human miR34a in cross-kingdom interaction of anti-tumoral response. Sci Rep 8: 12413.

138. Liang H, Zhang S, Fu Z, Wang Y, Wang N, et al. (2015) Effective detection and quantification of dietetically absorbed plant microRNAs in human plasma. $J$ Nutr Biochem 26: 505-512. [Crossref]

139. Chiang K, Shu J, Zemplent J, Cui J (2015) Dietary microRNA database (DMD): an archive database and analytic tool for food-borne microRNAs. PLoS One 10: e0128089. [Crossref]

140. Wang SS, Esplin ED, Li JL, Huang L, Gazdar A, et al. (1998) Alterations of the PPP2R1B gene in human lung and colon cancer. Science 282: 284-287. [Crossref]

141. Maupin-Furlow JA, Aldrich HC, Ferry JG (1998) Biochemical characterization of $20 \mathrm{~S}$ proteasome from the methanoarchaeon Methanosarcina thermophila. $J$ Bacteriol 180: 1480-1487. [Crossref]

142. Xia S, Zhang L, Cheng F, Feng Z, Lu L (2019) Expression of PSMA 7 and its effect on proliferation, invasion, migration and tumorigenesis of gastric cancer. Nan Fang Yi Ke Da Хue Xue Bao 39: 387-393. [Crossref]

143. Ocean AJ, Christos P, Sparano JA, Shah MA, Yantiss RK, et al. (2014) Phase II trial of bortezomib alone or in combination with irinotecan in patients with adenocarcinoma of the gastroesophageal or stomach. Invest New Drugs 32: 542-548. [Crossref]

144. Nam S, Kim JH, Lee DH (2019) RHOA in gastric cancer: functional roles and therapeutic potential. Front Genetics 10: 438. [Crossref]
145. Daubriac J, Han S, Grahovac J, Smith E, Hosein A, et al. (2018) The crosstalk between breast carcinoma-associated fibroblasts and cancer cells promotes RhoAdependent invasion via IGF-1 and PAT-1. Oncotarget 9: 10375-10387. [Crossref]

146. Duong KHM, Chun KH (2019) Regulation of glucose transport by RhoA in 3T3L1 adipocytes and L6 myoblasts. Biochem Biophys Res Commun 519: 880-886. [Crossref]

147. Ge F, Wang C, Wang W, Liu W, Wu B (2017) MicroRNA-31 inhibits tumor invasion and metastasis by targeting RhoA in human gastric cancer. Oncol Rep 38: 1133-1139. [Crossref]

148. Korourian A, Roudi R, Shariftabrizi A, Madjd Z (2017) MicroRNA-31 inhibits RhoA-mediated tumor invasion and chemotherapy resistance in MKN-45 gastric adenocarcinoma cells. Exp Biol Med 242: 1842-1847. [Crossref]

149. Shantz LM, Pegg AE (1998) Ornithine decarboxylase induction in transformation by H-Ras and RhoA. Cancer Res 58: 2748-2753.

150. Khosravi-Far R, Solski PA, Clark GJ, Kinch MS, Der CJ (1995) Activation of Rac1, RhoA, and mitogen-activated protein kinases is required for Ras transformation. $\mathrm{Mol}$ Cell Biol 15: 6443-6453. [Crossref]

151. Xie Y, Jin P, Sun X, Jiao T, Zhang Y, et al. (2018) SIX1 is upregulated in gastric cancer and regulates proliferation and invasion by targeting the ERK pathway and promoting epithelial-mesenchymal transition. Cell Biochem Funct 36: 413-419.

152. Barger CJ, Zhang W, Sharma A, Chee L, James SR, et al. (2018) Expression of the POTE gene family in human ovarian cancer. Sci Rep 8: 17136. [Crossref]

153. Wang Q, Li X, Ren S, Cheng N, Zhao M, et al. (2015) Serum levels of the cancertestis antigen POTEE and its clinical significance in non-small-cell lung cancer. PLoS One 10: e0122792. [Crossref]

154. Misawa A, Takayama K, Fujiwara T, Homma Y, Suzuki Y, et al. (2017) Androgeninduced IncRNA POTEF-AS1 regulates apoptosis-related pathway to facilitate cell survival in prostate cancer cells. Cancer Sci 108: 373-379. [Crossref]

155. Vekariya U, Rawat K, Saxena R, Tripathi RK (2019) Identification of MФ specific POTEE expression: its role in $\mathrm{mTORC} 2$ activation via protein-protein interaction in TAMs. Cell Immunol 335: 30-40. [Crossref]

156. Maoto MM, Beswa D, Jideani AI (2019) Watermelon as a potential fruit snack. Int J Food Prop 22: 355-370

157. Davis CD, Ross SA (2008) Evidence for dietary regulation of microRNA expression in cancer cells. Nutr Rev 66: 477-482. [Crossref]

158. Li D, Chen L, Zhao W, Hao J, An R (2016) MicroRNA-let-7f-1 is induced by lycopene and inhibits cell proliferation and triggers apoptosis in prostate cancer. $\mathrm{Mol}$ Med Rep 13: 2708-2714. [Crossref]

159. Gontero P, Marra G, Soria F, Oderda M, Zitella A, et al. (2015) A randomized double-blind placebo-controlled phase I-II study on clinical and molecular effects of dietary supplements in men with precancerous prostatic lesions: chemoprevention or "chemopromotion"? Prostate 75: 1177-1186. [Crossref]

160. Lima L, de Melo TC, Marques D, de Arajúo JN, Leite IS, et al. (2019) Modulation of all-trans retinoic acid-induced miRNA expression in neoplastic cell lines: a systematic review. BMC Cancer 19: 866. [Crossref]

161. Bouriez D, Giraud J, Gronnier C, Varon C (2018) Efficiency of all-trans retinoic acid on gastric cancer: a narrative literature review. Int J Mol Sci 19: 3388 [Crossref]

162. Chen PH, Shih CM, Chang WC, Cheng CH, Lin CW, et al. (2014) MicroRNA-302binhibited $\mathrm{E} 2 \mathrm{~F} 3$ transcription factor is related to all trans retinoic acid-induced glioma cell apoptosis. J Neurochem 131: 731-742. [Crossref]

Copyright: (C2019 Fujii YR. This is an open-access article distributed under the terms of the Creative Commons Attribution License, which permits unrestricted use, distribution, and reproduction in any medium, provided the original author and source are credited. 